\title{
Investigation on influence of antimony tin oxide/silver nanofluid on direct absorption parabolic solar collector
}

Sreekumar, S., Joseph, A., Kumar, C. S. S., \& Thomas, S. (2019). Investigation on influence of antimony tin oxide/silver nanofluid on direct absorption parabolic solar collector. Journal of Cleaner Production, 249. https://doi.org/10.1016/j.jclepro.2019.119378

Link to publication record in Ulster University Research Portal

\section{Published in:}

Journal of Cleaner Production

Publication Status:

Published (in print/issue): 22/11/2019

DOI:

https://doi.org/10.1016/j.jclepro.2019.119378

\section{Document Version}

Author Accepted version

\section{General rights}

Copyright for the publications made accessible via Ulster University's Research Portal is retained by the author(s) and / or other copyright owners and it is a condition of accessing these publications that users recognise and abide by the legal requirements associated with these rights.

\section{Take down policy}

The Research Portal is Ulster University's institutional repository that provides access to Ulster's research outputs. Every effort has been made to ensure that content in the Research Portal does not infringe any person's rights, or applicable UK laws. If you discover content in the Research Portal that you believe breaches copyright or violates any law, please contact pure-support@ulster.ac.uk. 


\title{
Investigation on the influence of antimony tin oxide/silver nanofluid on direct absorption parabolic solar collector
}

\author{
Sreehari Sreekumar ${ }^{\mathrm{a}}$, Albin Joseph ${ }^{\mathrm{b}}$, Sujith Kumar C. S ${ }^{\mathrm{a}}$, Shijo Thomas ${ }^{* b}$ \\ ${ }^{a}$ Department of Mechanical Engineering, National Institute of Technology Calicut, 673601, India \\ bshool of Materials Science and Engineering, National Institute of Technology Calicut, 673601, \\ India \\ Corresponding author: Shijo Thomas, Email address: shijo@ nitc.ac.in

\section{Abstract}

This paper discusses the synthesis and characterization of a novel hybrid nanofluid and its performance analysis on a parabolic trough direct absorption solar collector. Broadening the absorption spectra of working fluid using nanoparticles is the new research revolution for increasing the volumetric solar absorption efficiency. It is reported that plasmonic silver nanoparticles have higher absorption in visible spectra while antimony doped tin oxide has an absorption peak in the near-infrared region. Hence, antimony tin oxide/silver hybrid nanoparticle with broad spectral absorptivity was synthesized. Optimization of the nanofluid composition performed using response surface methodology yielded an optimized mass fraction of antimony tin oxide and surfactant, sodium dodecyl sulfate, as $0.1 \%$ each. The solar weighted absorption fraction of optimized nanofluid was obtained as $90.12 \%$. Performance evaluation of the solar collector was based on ASHRAE standards 93-2010. The optical efficiency of the parabolic collector was calculated to be $75 \%$. The maximum thermal efficiency obtained by the optimized nanofluid applied parabolic trough direct absorption solar collector was $63.5 \%$ at a flow rate of $0.022 \mathrm{kgs}^{-1}$ and the highest exergy efficiency obtained was $5.6 \%$. Thermal and exergy efficiency was observed to increase with increase in flow rate.

Keywords: ATO/Ag hybrid nanoparticle, solar weighted absorption fraction, optimization, direct absorption, photothermal conversion. 


\section{English Parameters}

\begin{tabular}{|c|c|c|c|}
\hline$A$ & Aperture area $\left[\mathrm{m}^{2}\right]$ & $K$ & Geometric factor \\
\hline$C_{p}$ & Specific heat $\left[J \mathrm{~kg}^{-1} K^{-1}\right]$ & $L_{a}$ & Receiver tube length $[m]$ \\
\hline$D_{\text {out }}$ & Outer diameter of the receiver $[m]$ & $\dot{m}$ & Mass flow rate $\left[k g s^{-1}\right]$ \\
\hline \multirow[t]{3}{*}{$d$} & Universal non-random error & $S_{\text {in }}$ & Entropy of heat transfer fluid at inlet $\left[\mathrm{kJ} \mathrm{kg}^{-1} \mathrm{~K}^{-1}\right]$ \\
\hline & parameter due to receiver mislocation & $s_{\text {out }}$ & Entropy of heat transfer fluid at outlet $\left[\mathrm{kJkg}^{-1} \mathrm{~K}^{-1}\right]$ \\
\hline & and reflector profile errors & $T_{a m b}$ & Ambient temperature $[K]$ \\
\hline$f$ & Focal distance $[m]$ & $T_{f m}$ & Mean fluid temperature $[K]$ \\
\hline \multirow[t]{2}{*}{$h_{\text {in }}$} & Enthalpy of heat transfer fluid at inlet & $T_{\text {in }}$ & Inlet temperature of heat transfer fluid $[K]$ \\
\hline & {$[k J]$} & $T_{\text {out }}$ & Outlet temperature of heat transfer fluid $[K]$ \\
\hline \multirow[t]{2}{*}{$h_{\text {out }}$} & Enthalpy of heat transfer fluid at outlet & $T_{S}$ & Temperature of the sun $[K]$ \\
\hline & {$[k J$} & $Q_{\text {sol }}$ & Solar radiation intensity $[W]$ \\
\hline$I$ & Solar intensity $\left[\mathrm{Wm}^{-2}\right]$ & $W_{a}$ & Aperture width $[m]$ \\
\hline$I_{\lambda}$ & Solar spectral intensity $\left[\mathrm{Wm}^{-2} \mathrm{~nm}^{-1}\right]$ & & \\
\hline
\end{tabular}

\section{Greek Parameters}

\begin{tabular}{|c|c|c|c|}
\hline$\alpha$ & Absorptance & $\lambda$ & Wavelength $[\mathrm{nm}]$ \\
\hline$\alpha_{\text {receiver }}$ & Absorbance of reflector & $\tau$ & Transmittance \\
\hline \multirow[t]{2}{*}{$\beta$} & non-random & $\tau_{\text {cover }}$ & Transmittance of the cover glass \\
\hline & parameter due to angular errors & $\varphi_{r}$ & Rim angle of collector $[\mathrm{rad}]$ \\
\hline$\gamma$ & Intercept factor & $\psi$ & Exergy $[W]$ \\
\hline$\eta_{e x}$ & Exergy efficiency & $\psi_{\text {dest }}$ & Exergy destruction rate $[W]$ \\
\hline$\eta_{t h}$ & Thermal efficiency & $\psi_{\text {in }}$ & Total exergy entering the system $[W]$ \\
\hline$\theta$ & Incidence angle $[\mathrm{rad}]$ & $\psi_{m, i n}$ & Exergy inflow rate by heat transfer fluid $[W]$ \\
\hline$\rho$ & Reflectance & $\psi_{m, \text { out }}$ & Exergy inflow rate by heat transfer fluid $[W]$ \\
\hline$\rho_{\text {collector }}$ & Reflectance of collector sheet & $\psi_{\text {out }}$ & Total exergy exiting the system $[W]$ \\
\hline$\sigma$ & Universal random-error parameter & $\psi_{\text {sol }}$ & Solar radiation exergy absorption rate $[W]$ \\
\hline
\end{tabular}




\section{Abbreviations}

ASTM American Society for Testing and NIR Near-infrared

Materials

PTDASC Parabolic Trough Direct Absorption Solar

ANOVA Analysis of Variance Collector

DOE Design of Experiments

RSM Response Surface Methodology

$\begin{array}{lll}\text { LSPR } & \text { Localized } & \text { Surface Plasmon } \\ & \text { Resonance } & \end{array}$

\section{Introduction}

Cleaner and sustainable energy technologies are gaining importance due to the increase in environmental pollution and the current energy demand. Solar energy is a reliable and promising one among the renewable energy resources. Researches on increasing the energy conversion efficiency of solar energy systems are taking place at a burgeoning speed. Photothermal, photochemical and photovoltaic conversions are the prominent methods of solar energy utilization. Photothermal systems are having the highest energy conversion efficiency among the other solar energy conversion techniques. Among the solar thermal systems, concentrating solar collectors are having higher thermal efficiency compared to non-concentrating collectors. A typical concentrating solar collector is based on three main steps: (i) concentrating the solar radiation on the receiver surface, (ii) energy conversion at the absorber surface and, (iii) heat transfer from absorber surface to working fluid by convection and conduction [1]. In such systems, the maximum temperature is occurring at the absorber surface immersed in water due to which the heat loss to the surrounding increases. They also show an increase in thermal resistance during heat transfer from the absorber surface to the working fluid. Direct absorption Solar Collectors (DASC) works on the principle of volumetric absorption of solar radiation. Since water and thermal oils have poor optical absorption properties, nanofluids are used in DASC. The energy gain of fluid by convective heat transfer from surface absorbers in a conventional solar collector is transformed into radiative transfer in a participating medium (nanofluid) in DASC. Synthesizing nanofluids with a higher photo-thermal conversion rate improves solar absorption efficiency. Vast research on synthesis, characterization, and testing of nanofluids with high thermal conductivity and optical absorptivity, like $\mathrm{Ag}, \mathrm{Au}$, carbon nanotubes $(\mathrm{CNT}), \mathrm{Cu}$, graphite, graphene, and metal oxides, have been performed. 
The concept of volumetric absorption was first proposed by Minardi et al. [2] in 1975. Tyagi et al. [3] were the first to propose a theoretical model for DASC. From the theoretical analysis, the direct absorption was found to have higher efficiency compared to surface absorption. Otanicar et al. [4] investigated the direct absorption capability of different base fluids by comparing their extinction coefficients and found water to better than thermal oils. Photothermal conversion of nanofluids synthesized using metal $(\mathrm{Cu}, \mathrm{Au}, \mathrm{Ag})$, metal oxide $\left(\mathrm{CuO}, \mathrm{Al}_{2} \mathrm{O}_{3}, \mathrm{TiO}_{2}\right)$ and nonmetal (GO, MWCNT) nanoparticles were performed over the years. Chen et al. [5] studied the photothermal conversion property of Au nanofluids and found that efficiency increased with an increase in the volume fraction of nanoparticle. Experimental analysis on the photothermal conversion property of gold nanofluids was performed by Beicker et al. [6]. Amjad et al. [7] analyzed the photothermal conversion capability of different nanofluids to be used for direct absorption applications. The results showed that silver nanofluid exhibited maximum energy conversion efficiency. Abdelrazika et al. [8] examined the influence of water-based silver transmittance of nanofluid decreased with an increase in collector depth and nanofluid volume fraction. Valizade et al. [9] performed an experimental investigation on direct absorption using nanofluids and metal foams of $\mathrm{CuO}$ and $\mathrm{SiC}$ material. Nanofluid absorber exhibited enhancement over its respective metal foam in the case of copper oxide. Chen et al. [10] performed photothermal conversion investigations on cupric oxide $(\mathrm{CuO})$ and antimony tin oxide (ATO) binary nanofluid. ATO provided complementary optical absorption due to its better solar absorption at near-infrared (NIR) spectra. Investigation performed by $\mathrm{Yu}$ et al. [11] concluded that the dispersion stability of nanofluid is having a direct impact on optical absorptivity. Even though the property of base fluid could be enhanced by addition of nanoparticle, there are some limitations. Some of the drawbacks associated with nanofluids are the higher cost, time-consuming nanofluid synthesis process, lesser stability, and higher viscosity.

A hybrid nanoparticle has an advantage over mono-component nanoparticle as it exhibits synergetic properties of the multiple components present in the structure. Property tunability at particle level is the advantage of hybrid nanofluid over binary nanofluid. According to the authors' knowledge hybrid nanoparticles with selective spectral absorptivity are less explored. Yu et al. [12] synthesized $\mathrm{CuO} / \mathrm{Ag}$ composite nanoparticle for solar direct absorption application. Jiang et al. [13] synthesized $\mathrm{Ag}-\mathrm{Ag}_{2} \mathrm{~S}$ core-shell structure with broad absorption spectra which exhibited 
an absorption peak in the wavelength range of $300 \mathrm{~nm}-1100 \mathrm{~nm}$. Zeng et al. [14] synthesized $\mathrm{Sn} / \mathrm{SiO}_{2} / \mathrm{Ag}$ core-shell PCM nanoparticle for thermal energy storage and solar absorption. Zeng et al. [15] synthesized silver-based $\mathrm{SiO}_{2} / \mathrm{Ag}$ plasmonic hybrid nanofluid and its binary nanofluid with NIR absorbing MWCNT nanoparticle. Zeng et al. [16] synthesized a full spectrum absorption hybrid nanoparticle. Visible spectrum absorbing TiN nanoparticle and NIR absorbing magnetic $\mathrm{Fe}_{3} \mathrm{O}_{4}$ nanoparticle was selected as hybrid material components. This was one of the few papers on full spectral absorption hybrid nanoparticle.

Design of experiments (DoE), fuzzy logic and artificial neural network (ANN) are the most preferred tools for finding the interaction of input parameters on the output response. Out of these, DoE will provide an insight into the dependence of response on input parameters in a minimum number of experiments [17]. Esfe et al. [18] optimized the rheological and thermal properties of $\mathrm{Al}_{2} \mathrm{O}_{3}$-EG/water nanofluid by using response surface methodology (RSM).

The advantage of a DASC is that the maximum temperature is occurring within the fluid volume and hence the need for a hotter absorber tube surface can be avoided. In addition, the energy efficiency of the collector could be improved by increasing the solar spectral absorptivity of nanofluid by modifying the morphology, material property (thermal and optical) and mass fraction of the nanomaterial. The thermo-economic analysis was conducted on the performance of a DASC by Otanicar et al. [19]. The studies compared the economic and environmental impact of DASC on residential water heating applications and proved that in addition to $3 \%$ improvement in thermal efficiency of the collector, the DASCs are providing the same economic benefit as a conventional collector. Applicability of hybrid nanofluid in conventional parabolic trough collectors was extensively reviewed by Minea et al. [20]. However, experimental investigations performed on DASC using hybrid nanofluids are very rare compared to single and binary nanofluids. Bellos et al. [21] performed an investigation on the performance of a parabolic trough collector using oil-based $\mathrm{Al}_{2} \mathrm{O}_{3}-\mathrm{TiO}_{2}$ hybrid nanofluid. The analysis shows that enhancement in the thermal efficiency of PTC using hybrid nanofluid was higher than the mono nanofluids. Delfani et al. [22] conducted experimental and numerical analysis on the thermal performance of MWCNT nanofluid based DASC for residential application and reported an improvement of 10-29\% in thermal efficiency, over that of the base fluid. The efficiency was found to be an ascending function of volume fraction and flow rate. Vakili et al. [23] evaluated flat plate 
DASC with graphene nanoplatelets as working fluid for domestic water heating applications. The maximum thermal efficiency was obtained at an optimum mass flow rate of $0.015 \mathrm{kgs}^{-1}$. Menbari et al. [24] on examining $\mathrm{CuO}$ as working fluid in PTDASC found that thermal efficiency of 52\% was achievable by varying volume fraction of the nanofluid. Menbari et al. [25] performed an experimental analysis on $\mathrm{CuO} / \mathrm{Al}_{2} \mathrm{O}_{3}$ binary nanofluid being applied in PTDASC. The thermal efficiency of PTDASC having binary nanofluid was found to be $48 \%$. Although numerous works on energy analysis of DASCs has been reported, experimental works on the exergy analysis on direct absorption solar collectors are very few. An extensive review of the exergy analysis of solar collectors and its significance on the performance investigation was performed by Kalogirou et al. [26]. Gorji and Ranjbar [27] carried out thermal exergy analysis on DASC for optimizing the performance parameters of the system. Response surface methodology was used for optimizing the parameters like incident solar flux, nanofluid volume fraction and flow rate. Maryam Karami [28] reported an enhancement in the thermal efficiency of $21.7 \%$ for DASC with hybrid nanofluid over the base fluid.

From the literature review, it is clearly inferred that most of the hybrid nanoparticles synthesized have $\mathrm{Ag}$ as one of its components due to its LSPR effect. ATO is a viable option for nanoparticles with NIR absorption [10]. Among the available base fluids, water is reported to be having the highest optical absorptivity [4]. Investigations on hybrid nanofluids with wide spectrum solar absorption in PTDASC is also very limited in the reported literature. Design of Experiments (DoE) could be adopted as a useful tool for the optimization of parameters based on output response with a minimal number of experiments.

In this work, synthesis, characterization, and optimization of a novel ATO/Ag hybrid nanoparticle having broad spectral absorption property are performed. Based on the design of experiments concept a design matrix was created with different mass fractions of components based on which the synthesis and characterization of nanofluids were performed. Response surface methodology was adopted for finding the effect of nanoparticle and surfactant mass fractions on the solar weighted absorption fraction of nanofluid. The optimized mass fraction and surfactant concentration were calculated using the desirability function in 'Design Expert' software. Parametric study was also performed to analyze the effect of mass fraction of nanoparticle and the 
penetration depth of light on optical absorptivity. Experimental investigations were conducted on optimized hybrid nanofluid based PTDASC and, energy and exergy analysis were performed.

\section{Synthesis and characterization of hybrid nanoparticle}

\subsection{Synthesis of ATO/Ag hybrid nanoparticle}

ATO nanoparticle was supplied by Sigma Aldrich. The hybrid nanoparticle is synthesized using facile one-step reduction reaction [15, 29] using $\mathrm{Sb}_{2} \mathrm{O}_{5}, \mathrm{SnCl}_{2}, \mathrm{HCl}, \mathrm{AgNO}_{3}$ and $\mathrm{ATO}$ nanoparticles (Sigma Aldrich). The ATO nanoparticles are dispersed in a medium of pH greater than its isoelectric point (IEP). The IEP of tin oxide is in a range of +2 and +4 while the IEP of $\mathrm{Sb}_{2} \mathrm{O}_{5}$ lies between +3 and +5 [30]. IEP of ATO lies in between the constituents. Hence the particles will gain a negative charge on dispersion in base fluid [15]. $200 \mathrm{~g}$ of $\mathrm{SnCl}_{2}$ and $300 \mu \mathrm{l}$ of $\mathrm{HCl}$ are mixed in $40 \mathrm{ml}$ of DI water, and then ATO nanoparticles are dispersed in this medium. The $\mathrm{pH}$ of the reaction environment is adjusted by rinsing in water continuously. $\mathrm{pH}$ is set to 7 for further reaction process. ATO surface will have a negative charge in this reaction environment. ATO nanoparticle is activated with $\mathrm{Sn}^{2+}$ by inorganic grafting between $\mathrm{OH}^{-}$groups on the surface [29]. $\mathrm{AgNO}_{3}$ solution of $40 \mathrm{ml}$ is prepared and mixed with the above solution. ATO/Sn ${ }^{2+}$ wet mixture on reaction with silver nitrate solution undergoes a reduction process to produce $\mathrm{Ag}+$ ions in solution. The charge difference is the potential for Ag deposition on the surface of ATO [29]. Finally, the deposited ATO/Ag nanoparticle is washed and dried in a hot air oven maintained at $60^{\circ} \mathrm{C}$. The synthesis process is graphically represented in Fig. 1.

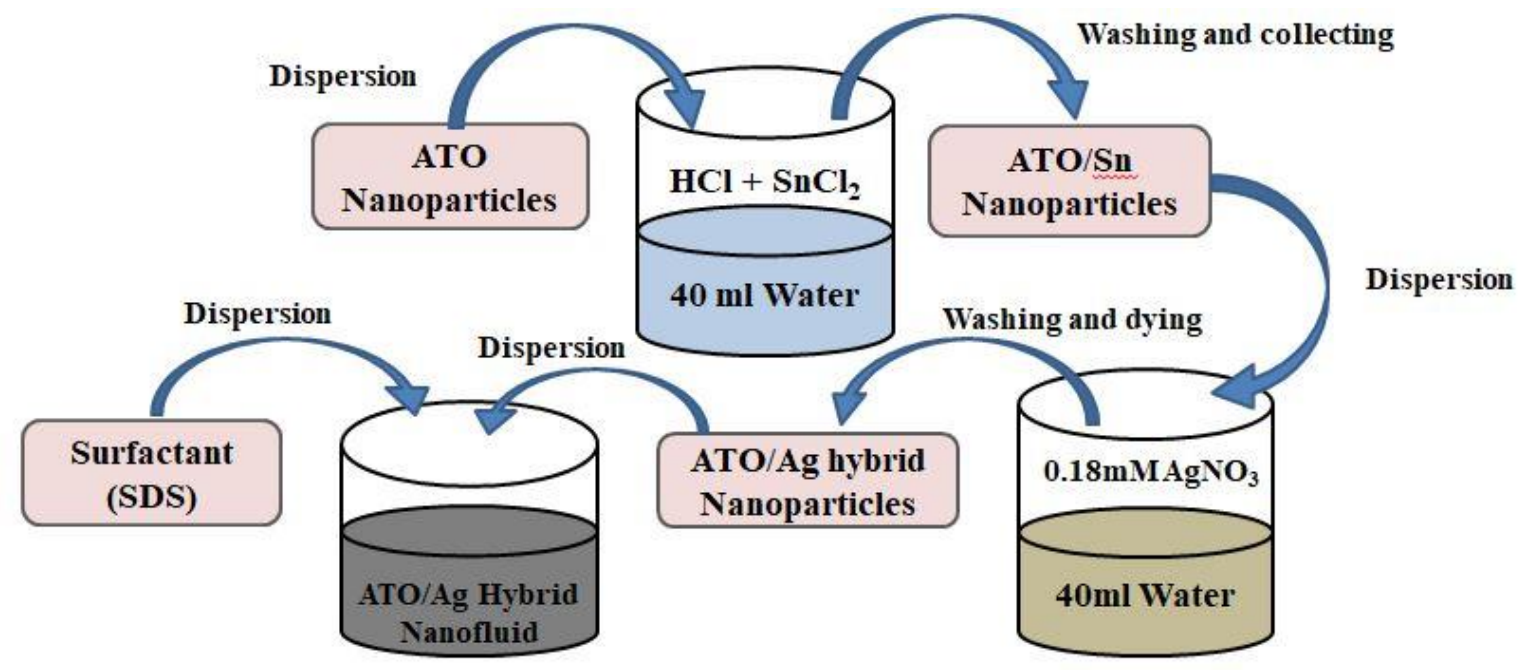

Fig. 1. Methodology used in the synthesis of ATO/Ag nanoparticle and nanofluid 


\subsection{Morphological characterization}

165 Morphological characterization of nanoparticle was done using high-resolution transmission 166 electron microscopy (Jeol/JEM 2100) and scanning electron microscopy (Zeiss HV $\Sigma$ IGMA 167 FESEM). Morphological analysis carried out using the SEM image given by Fig. 2 shows that the 168 ATO nanoparticles are not fully spherical. The size of ATO/Ag nanoparticles is varying in the 169 range of $20-50 \mathrm{~nm}$. As observed in Fig. 2, it is obvious that the size of the Ag nanoparticle is less 170 than $10 \mathrm{~nm}$. The SEM image of ATO/Ag hybrid nanoparticles is seen to be in a clustered form due 171 to its smaller size. The TEM image of hybrid nanoparticle as displayed in Fig. 3 confirms the 172 deposition of $\mathrm{Ag}$ on the surface of ATO nanoparticle. SEM image is unable to show the 173 crosslinking between the particles as the size of particles falls below 40nm and the shape of 174 particles is not spherical. Hence the SEM-EDAX is performed to show the presence of silver 175 particles in the as-prepared particle sample.

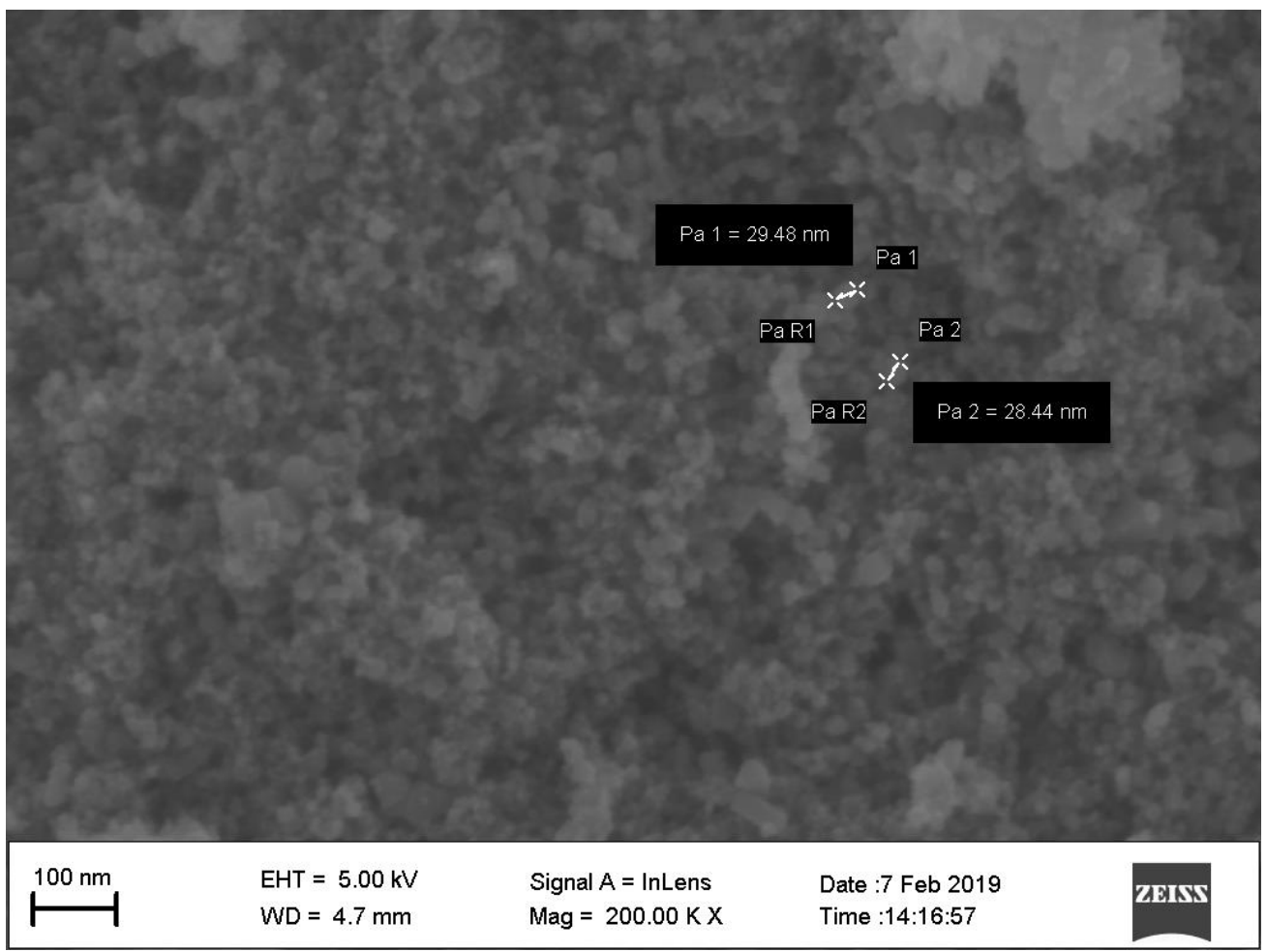

Fig. 2. SEM images of ATO/Ag hybrid nanoparticle 


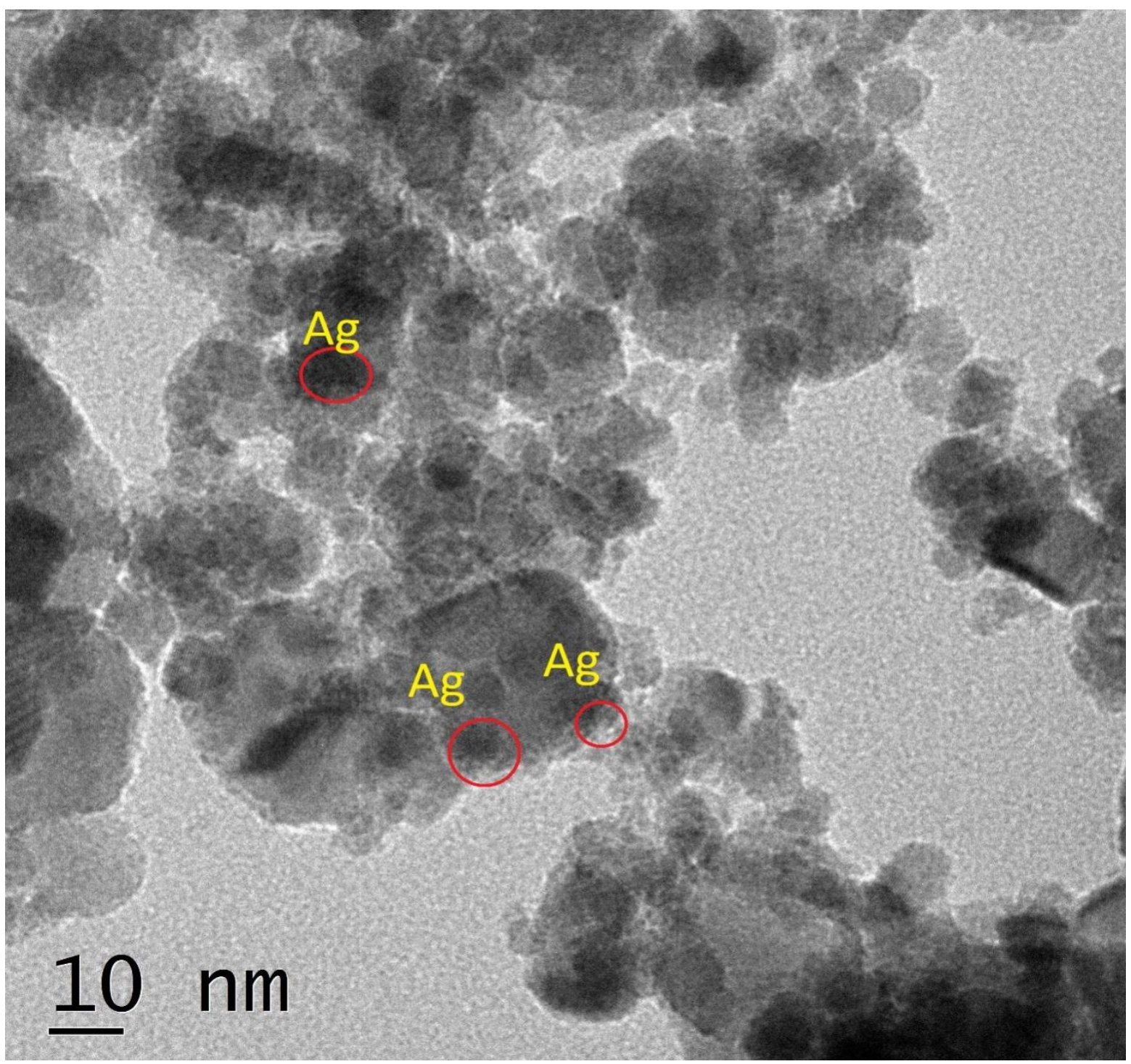

Fig. 3. TEM image of ATO/Ag hybrid nanoparticle

2.3. Phase structure analysis of hybrid nanoparticle

183 The XRD spectrum of ATO/Ag hybrid nanoparticle and ATO nanoparticles are shown in Fig 4. 184 ATO nanoparticle is having tetragonal rutile structure. The major peaks of ATO nanoparticle 185 corresponding to (100), (101), (200) and (211) crystallographic planes (JCPDS 88-0287) were 186 observed in the XRD analysis. The peaks of Ag nanoparticle (JCPDS 04-0783) with FCC structure 187 confirm the presence of Ag. FCC structured silver nanoparticle is having peaks that are indexed to 188 its (111), (200), (220) and (311) crystallographic planes. 

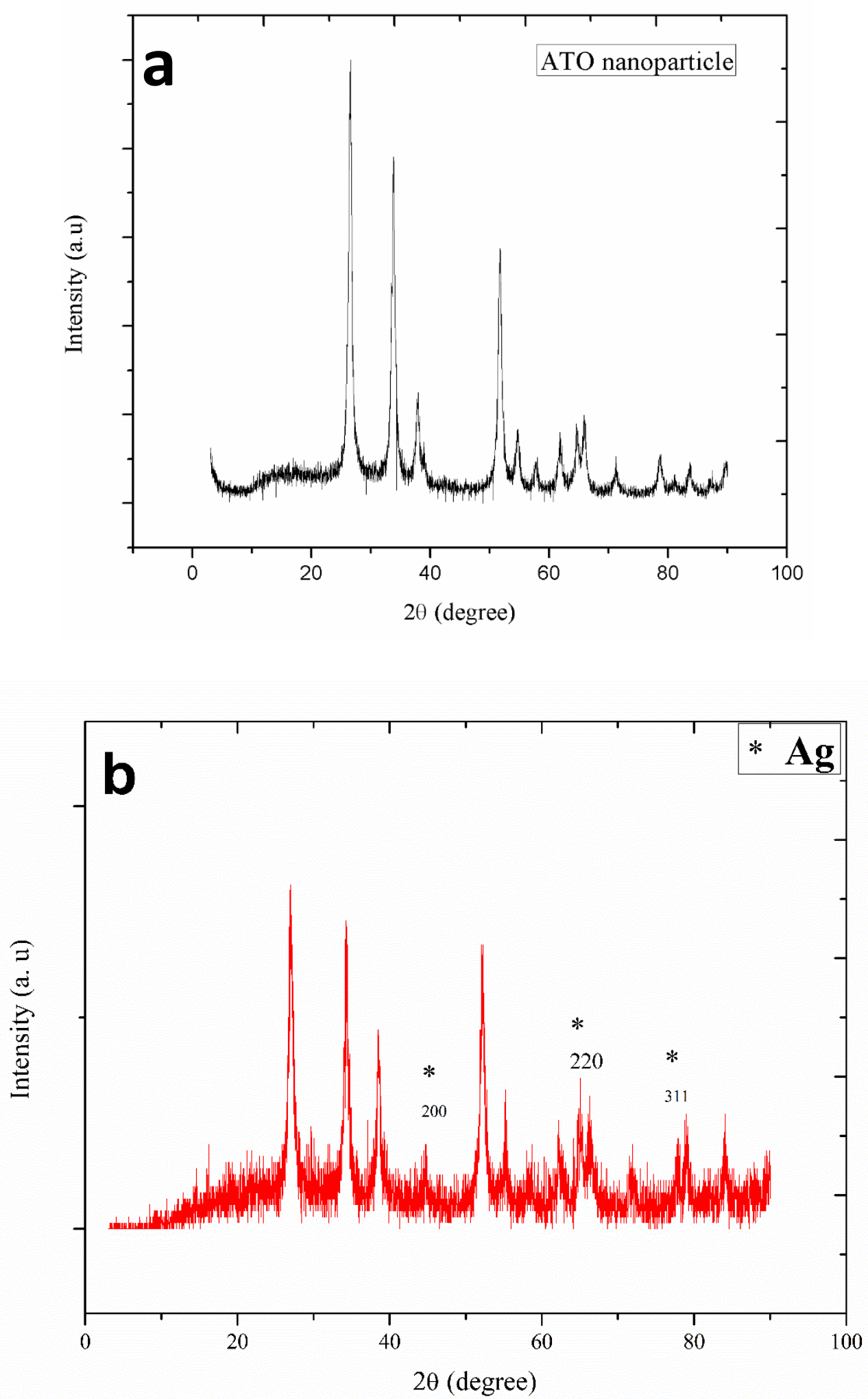

Fig. 4. XRD spectrum of (a) ATO nanoparticle, (b) ATO/Ag hybrid nanoparticle 


\subsection{Composition analysis of hybrid nanoparticle}

193 Energy-Dispersive X-ray (EDAX) spectroscopic analysis is used to perform the elemental 194 mapping of constituent elements present in a material. The composition of different elements of 195 the synthesized hybrid nanomaterial was found by analyzing the X-rays emitted after bombarding 196 with the electron beam from the test sample. Fig. 5 depicts the elemental distribution and 197 composition in the ATO/Ag hybrid nanomaterial sample. The EDX spectroscopic results, as 198 observed from Fig. 5, can also be used to confirm the presence of proposed elements in the hybrid 199 material. The presence of ATO nanoparticle is confirmed by the occurrence of its main elements, $200 \mathrm{Sn}$ and $\mathrm{Sb}$, which are having the maximum mass fractions of $66 \%$ and $10 \%$. Ag which has $3 \%$ of 201 mass fraction in the hybrid nanoparticle sample is also uniformly distributed in the sample, as 202 observed from the mapping. As the size of the silver nanoparticle is almost half of ATO, the silver 203 content in the area is less as observed from the mapping. From Fig. 5, it is inferred that the hybrid 204 nanoparticles of the required components are synthesized, and have an even distribution of 205 particles in the prepared sample. 

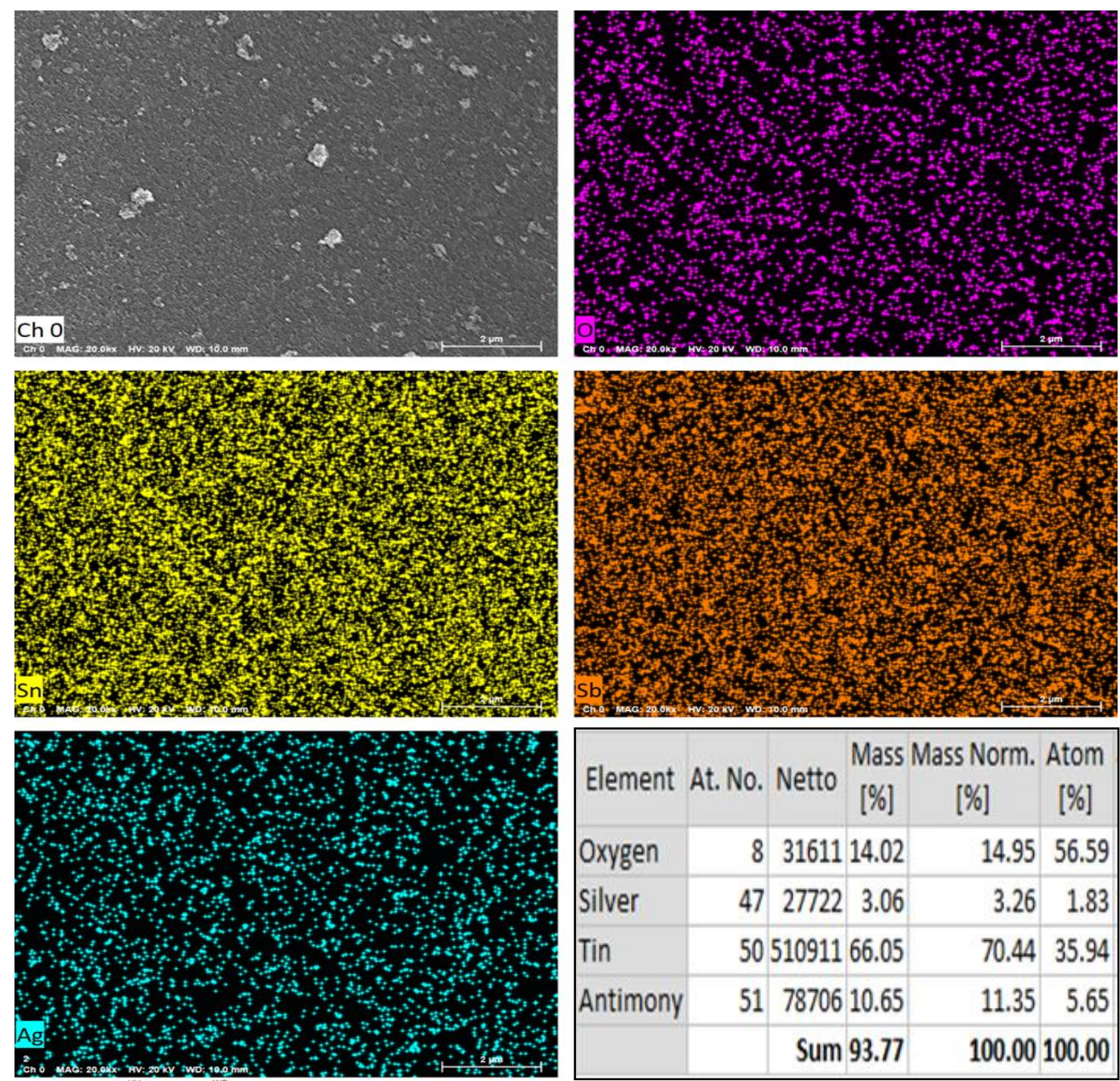

\begin{tabular}{|c|c|c|c|c|c|}
\hline \multirow[b]{2}{*}{ Element } & \multirow[b]{2}{*}{ At. No. } & \multirow[b]{2}{*}{ Netto } & \multicolumn{2}{|c|}{ Mass Mass Norm. } & \multirow{2}{*}{$\begin{array}{c}\text { Atom } \\
{[\%]}\end{array}$} \\
\hline & & & {$[\%]$} & {$[\%]$} & \\
\hline Oxygen & 8 & 31611 & 14.02 & 14.95 & 56.59 \\
\hline Silver & 47 & 27722 & 3.06 & 3.26 & 1.83 \\
\hline Tin & 50 & 510911 & 66.05 & 70.44 & 35.94 \\
\hline \multirow[t]{2}{*}{ Antimony } & 51 & 78706 & 10.65 & 11.35 & 5.65 \\
\hline & & Sum & 93.77 & 100.00 & 100.00 \\
\hline
\end{tabular}

Fig. 5: FESEM-EDAX mapping of ATO/Ag hybrid nanoparticle and composition table

\section{3. Synthesis and characterization of Nanofluid}

\subsection{Preparation of nanofluid}

210 The ATO/Ag hybrid nanoparticle is dispersed in DI water at the required mass fractions. For

211 improving the stability of the prepared nanofluid, Sodium Dodecyl Sulfate (SDS) is added as

212 surfactant. The addition of SDS as a surfactant produces surface charge on the particle which

213 prevents the agglomeration of nanoparticles, thereby providing a highly stable and fully dispersed

214 nanofluid. The surfactant-induced electrostatic dispersion stability is due to reduced inter-particle

215 interaction [11]. 
Reducing the number of experiments to arrive at the optimum composition of ATO, Ag, 217 and SDS is required to minimize the usage and waste of various chemicals. For obtaining the optimum composition that yields maximum optical absorption, response surface methodology 219 (RSM) in Design Expert 10 was employed. RSM provides a clear insight of input variables

\section{9} interaction on output response using a minimum number of experimental runs [17]. The parameters considered for optimization are the concentrations of nanoparticle and surfactant. The mass fraction was varied from 0.01 to $0.2 \%$ for ATO/Ag nanoparticle and 0.1 to $0.2 \%$ for SDS. The maximum limit of SDS concentration is selected so that the Critical Michelle Concentration $(\mathrm{CMC})$ point is not reached. The maximum concentration of nanoparticles was selected based on the literature survey on the same individual nanoparticles. An increase in concentration was reported to increase the thermal conductivity but favors agglomeration. Hence the range that was reported in the literature to provide maximum absorption was taken as the limits of nanoparticles in the design matrix to find the optimum concentration. Stability analysis of the colloidal solution was performed for the mono-component ATO nanofluid, ATO/Ag hybrid nanofluid with optimized mass fraction and, ATO/Ag hybrid nanofluid with the maximum concentration of ATO/Ag from the design matrix as described in section 5.4.

According to the design matrix given in Table 1, different combinations of ATO, Ag, and SDS are subjected to spectroscopic analysis. Nine different combinations of constituent mass fractions and four same combinations of component mass fractions are presented in Table 1. A combination which is the mean of high and low levels is repeating four times in the design matrix. The reproducibility of the results is verified by cross-checking with the results obtained for repeated combinations. The response parameter based on which the optimized combination is arrived at is the solar weighted absorption fraction. 
Table 1: Design matrix for preparing nanofluids with combinations of mass fraction

\begin{tabular}{ccc}
\hline Run & \multicolumn{2}{c}{ Input Variables } \\
\cline { 2 - 3 } & $\begin{array}{c}\text { ATO/Ag (\% mass } \\
\text { fraction) }\end{array}$ & SDS \\
& 0.01 & 0.15 \\
1 & 0.11 & 0.15 \\
2 & 0.11 & 0.1 \\
3 & 0.11 & 0.15 \\
4 & 0.11 & 0.15 \\
5 & 0.04 & 0.11 \\
6 & 0.17 & 0.19 \\
7 & 0.11 & 0.2 \\
8 & 0.04 & 0.19 \\
9 & 0.17 & 0.11 \\
10 & 0.2 & 0.15 \\
11 & 0.11 & 0.15 \\
12 & 0.11 & 0.15 \\
13 & &
\end{tabular}

\subsection{Thermal conductivity}

247 The thermal conductivity of the samples was measured with the KD2 Pro Thermal Property Meter 248 (Decagon Devices). The KD2 Pro uses a transient line heat source method to obtain the transient 249 temperature profile of fluid which is then compared with the full exponential integral solution of 250 the heat equation to obtain the thermal conductivity. The measurements are done at a constant 251 temperature of $29.5^{\circ} \mathrm{C}$ for all samples. Three sets of readings were made for each sample and the 252 average is taken as given in Table 2. The results reveal that the thermal conductivity of hybrid 253 nanofluid samples is not a linear function of the concentration of nanoparticle and surfactant. 254 Thermal conductivity values are given in Table 2. 


\subsection{Optical property characterization}

257 UV-Vis spectrophotometer (SHIMADZU) with a spectral range of 280nm-1200nm is used for the 258 optical characterization of the nanofluids. The wavelength range is sufficient in analyzing the 259 optical absorptivity of broad-band spectral absorbing nanofluids as the complete extinction of 260 radiation takes place in this spectral range $[13,31]$.

261

Table 2: Thermal conductivity and solar weighted absorption fraction of nanofluids

\begin{tabular}{|c|c|c|c|c|}
\hline \multirow[b]{2}{*}{ Run } & \multicolumn{2}{|c|}{ Input Variables } & \multicolumn{2}{|c|}{ Responses } \\
\hline & $\begin{array}{l}\text { ATO/Ag } \\
\text { (\% mass } \\
\text { fraction) }\end{array}$ & $\begin{array}{c}\text { SDS } \\
\text { (\% mass } \\
\text { fraction) }\end{array}$ & $\begin{array}{c}\text { Solar Weighted } \\
\text { absorptivity } \\
(\%) \\
\text { (Error range } \\
\pm 1.01 \%)\end{array}$ & $\begin{array}{l}\text { Thermal conductivity } \\
\qquad\left(\mathbf{W m}^{-1} \mathbf{K}^{-1}\right) \\
\text { (Error range } \pm \mathbf{5 \%} \text { ) }\end{array}$ \\
\hline 1 & 0.01 & 0.15 & 53.05 & 0.64 \\
\hline 2 & 0.11 & 0.15 & 85.15 & 0.6654 \\
\hline 3 & 0.11 & 0.1 & 91.63 & 0.65941 \\
\hline 4 & 0.11 & 0.15 & 83 & 0.665 \\
\hline 5 & 0.11 & 0.15 & 82.5 & 0.6656 \\
\hline 6 & 0.04 & 0.11 & 74.03 & 0.64808 \\
\hline 7 & 0.17 & 0.19 & 95.05 & 0.6665 \\
\hline 8 & 0.11 & 0.2 & 82.6 & 0.65941 \\
\hline 9 & 0.04 & 0.19 & 70.289 & 0.6491 \\
\hline 10 & 0.17 & 0.11 & 93.54 & 0.667 \\
\hline 11 & 0.2 & 0.15 & 98.9 & 0.67 \\
\hline 12 & 0.11 & 0.15 & 84 & 0.6655 \\
\hline 13 & 0.11 & 0.15 & 85.99 & 0.6654 \\
\hline
\end{tabular}

263 The analysis is done in the wavelength corresponding to the solar spectrum ranging from visible 264 to NIR range $(280-1200 \mu \mathrm{m})$. The optical path length of the beam is fixed as $10 \mathrm{~mm}$. Beer-Lamberts 
law given by Eq. (1) is used to find the extinction coefficient $\left(K_{e}\right)$ of nanofluid from spectral transmittance coefficient $(\tau(\lambda))$, assuming that reflection and scattering are negligible.

$$
\tau_{\lambda}=e^{-y K_{e}}=1-\alpha_{\lambda}
$$

Transmittance spectra of nanofluids and the base fluid are shown in Fig. 6. The transmittance of nanofluid is compared with base fluid to indicate the decrease in transmittance ratio along the spectrum. Transmittance exhibited by nanofluid samples is showing a steep decrease at visible spectrum $(350 \mathrm{~nm}-450 \mathrm{~nm})$ and NIR spectrum $(950 \mathrm{~nm}-1050 \mathrm{~nm})$. This decrease in transmittance is due to the synergetic effect of ATO/Ag hybrid nanofluid having absorption peaks in the visible region $(400 \mathrm{~nm})$ and NIR region $(1000 \mathrm{~nm})$. Transmittance spectra can be considered to verify the presence of materials with absorption peaks in these above reported spectral range. From the transmittance spectra, radiative transmittance is observed to be a descending function of nanoparticle mass fraction. The highest transmittance is produced by the nanofluid with the least concentration $(0.01 \%$ ATO/Ag). Least transmittance was provided by nanofluid with maximum nanoparticle mass fraction (0.2\% ATO/Ag). For two samples, Run 6 (0.04\% ATO/Ag 0.19\% SDS) and Run $9(0.04 \%$ ATO/Ag $0.11 \%$ SDS $)$, with the same mass fraction of ATO/Ag, transmittance was found to be lower for the sample with lesser surfactant mass fraction. This trend of higher absorption at lower surfactant concentration is repeating for the two other samples, Run 7 (0.17\% ATO/Ag, 0.19\% SDS) and Run 10 (0.17\% ATO/Ag, 0.11\% SDS), with the same mass fraction. Noise observed in transmittance spectra above $1100 \mathrm{~nm}$ is due to the instrument.

The percentage of solar energy absorbed by the nanofluid volume is represented by the solar-weighted absorption fraction (Sm) calculated using Eq. (2) suggested by Drotning [32].

$$
\operatorname{Sm}=\frac{\int_{0}^{\lambda} I_{\lambda} \alpha_{\lambda} d \lambda}{\int_{0}^{\lambda} I_{\lambda} d \lambda}
$$

Fig. 7 depicts the spectral solar irradiance of nanofluid samples along with the reference spectrum. ASTM G-173 [32] at AM 1.5 standard is used as the reference spectra. Solar weighted absorptivity graph, when coinciding with reference spectra indicates a $100 \%$ radiation absorption by a nanofluid. The maximum solar absorption of $98.90 \%$ is displayed by Run 11 corresponding to the sample with the highest nanoparticle mass fraction $(0.2 \%)$. The lowest spectral absorption is showed by the sample (Run 1) with the least concentration of nanoparticle $(0.01 \%)$. 


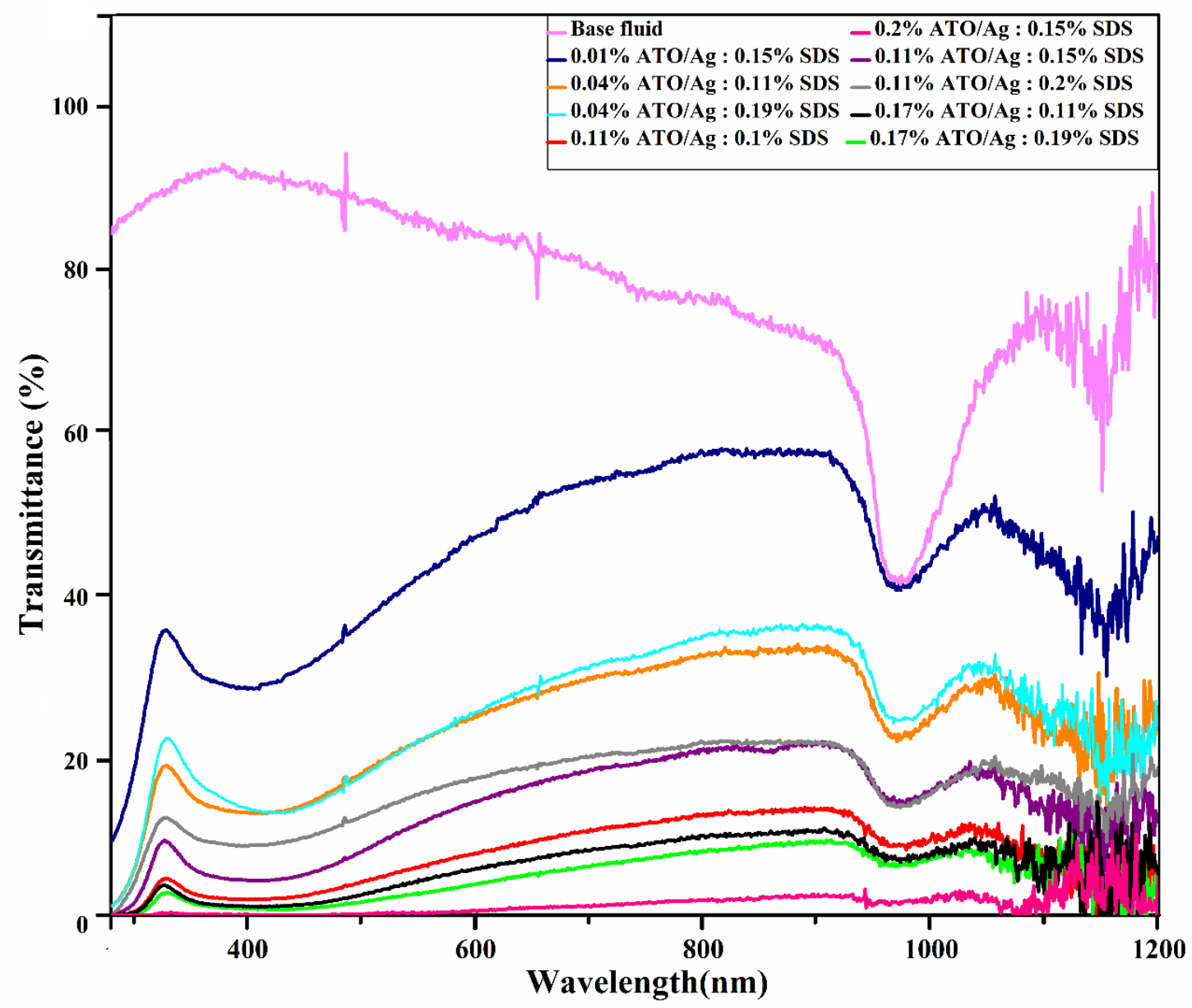

Fig. 6. Transmittance of nanofluid samples (Run 1, 2, 3, 6, 7, 8, 9, 10, 11) and water 


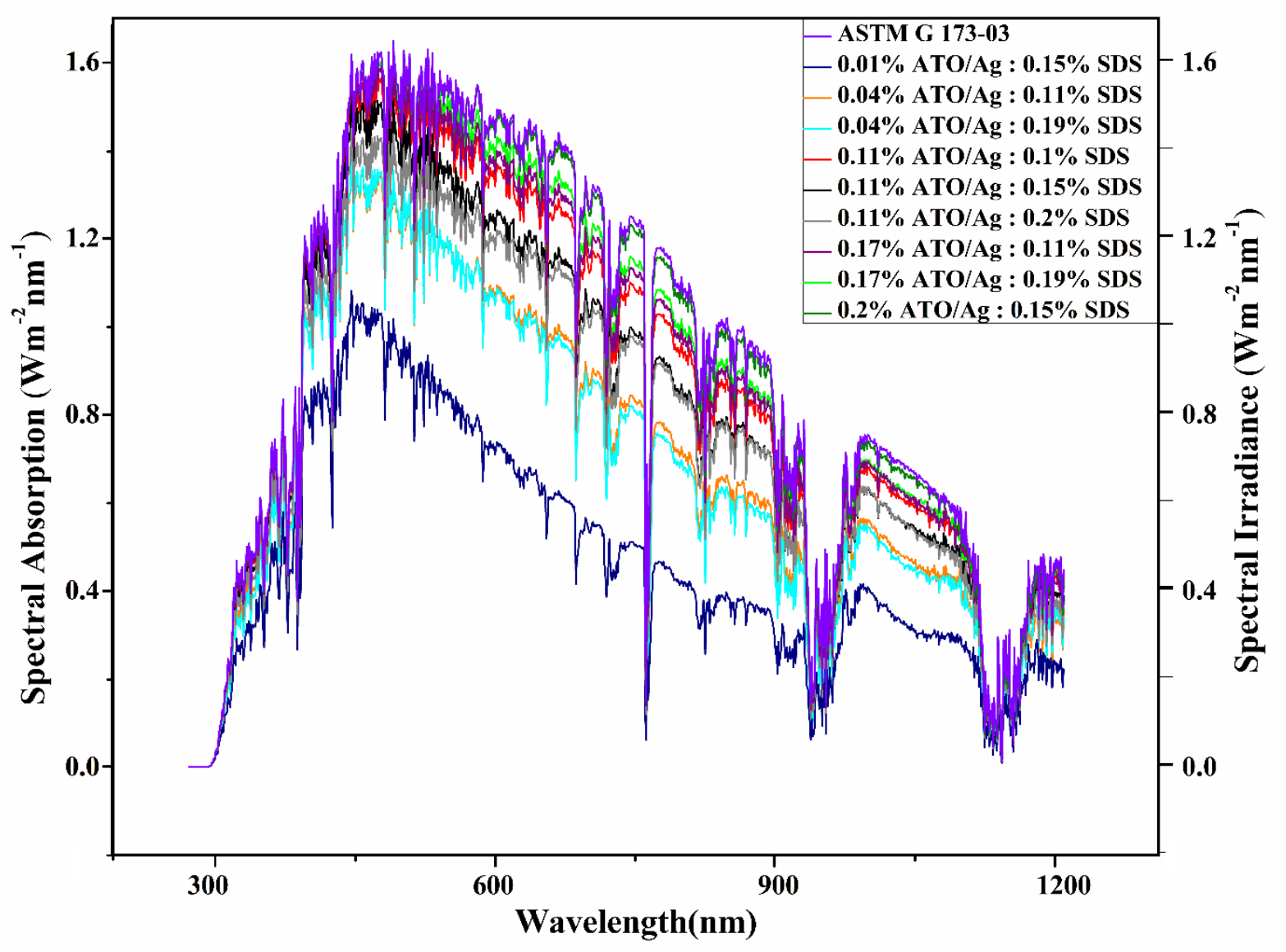

Fig. 7. Spectral irradiance of reference and nanofluid samples

\section{Parametric study}

\subsection{Effect of penetration depth on solar weighted absorption fraction}

297 The transmittance of nanofluid decreases with an increase in the penetration depth of radiation.

298 Beer-Lambert law was used for studying the dependence of solar weighted absorption fraction on 299 penetration depth. As observed in Fig. 8, the solar weighted absorption fraction is increasing exponentially with an increase in penetration distance. The influence of penetration depth on solar

301 weighted absorption fraction is studied in a range of $0.2-10 \mathrm{~cm}$. Longer penetration distance 302 provides improvement in solar weighted absorption fraction even though the concentration of nanofluid is less. Run 1 is having the lowest value of $S_{m}$ at each penetration depth. From the variation of $S_{m}$ plotted it is clearly observed that nanofluid with lesser concentration of 
nanoparticles at shorter penetration depth is not preferred. A higher concentration of nanoparticle at longer penetration depth is also not advisable as the chances of agglomeration are prevalent.

Nanofluids with nanoparticle concentrations of $0.11 \%$ and above are having a solar weighted absorption percentage of $90-100 \%$ for penetration depth above $1.5 \mathrm{~cm}$. Therefore, the dimension for nanofluid receiver volume must be above the optimum depth of penetration. The depth of penetration is not preferred to be increased much beyond the optimum depth as heat losses increase with an increase in surface area. Also, at higher optical path length, the complete radiation will be absorbed above a certain height and the resultant heat developed would have to be conducted to the remaining volume. Hence, it can be concluded that the optimum concentration at optimum penetration depth is required. In the present PTDASC system, since the inner diameter of the glass tube is $1.5 \mathrm{~cm}$, it can be ensured that the extinction taking place in the fluid volume is greater than $95 \%$ for nanofluids with nanoparticle concentrations of $0.11 \%$ and above.

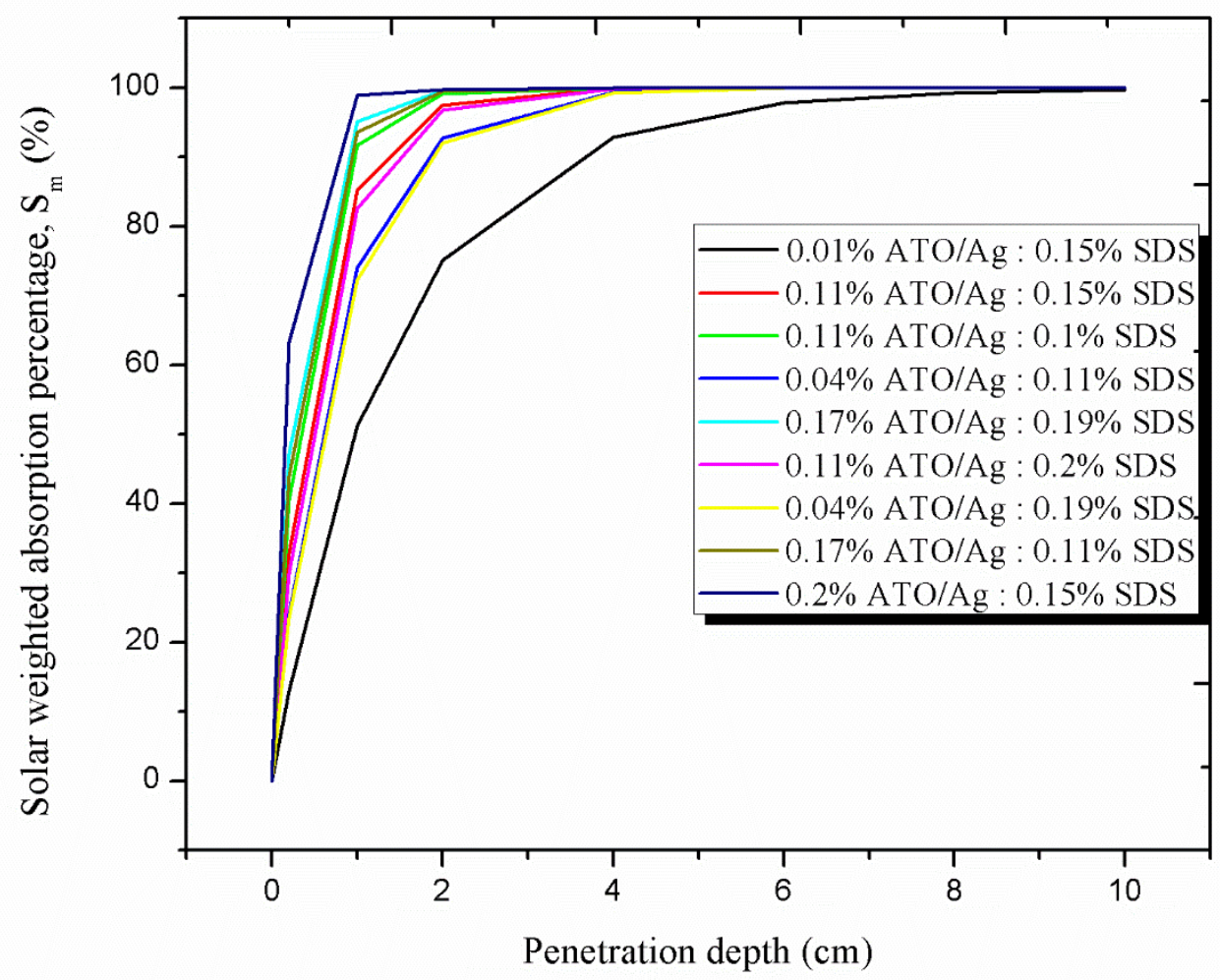

Fig. 8. Variation of solar weighted absorption percentage with penetration depth

\subsection{Effect of mass fraction on the extinction coefficient}


320 The effect of the mass fraction of nanoparticle on the extinction coefficient of nanofluid was

321 investigated and plotted as given in Fig. 9. The investigations were performed on concentrations

322 of nanoparticles corresponding to maximum $(0.2 \%)$, average $(0.11 \%)$ and minimum $(0.01 \%)$, at

323 wavelengths ranging from $300 \mathrm{~nm}$ to $900 \mathrm{~nm}$. As observed in Fig. 9, the extinction coefficient is

324 observed to be approximately a linear function of the mass fraction. Hence, absorption efficiency

325 is increasing with optical path length for a specified concentration and, with increasing

326 concentration for a specified light path length. Surmising from the parametric analysis, the solar

327 radiation can be absorbed by either increasing the concentration or optical depth of penetration.

328 By controlling the mass fraction of nanoparticle, the solar radiation can be absorbed completely

329 for a specific optical depth. An error bar is also provided with the extinction curve to show the

330 deviation involved in the measurement of values.

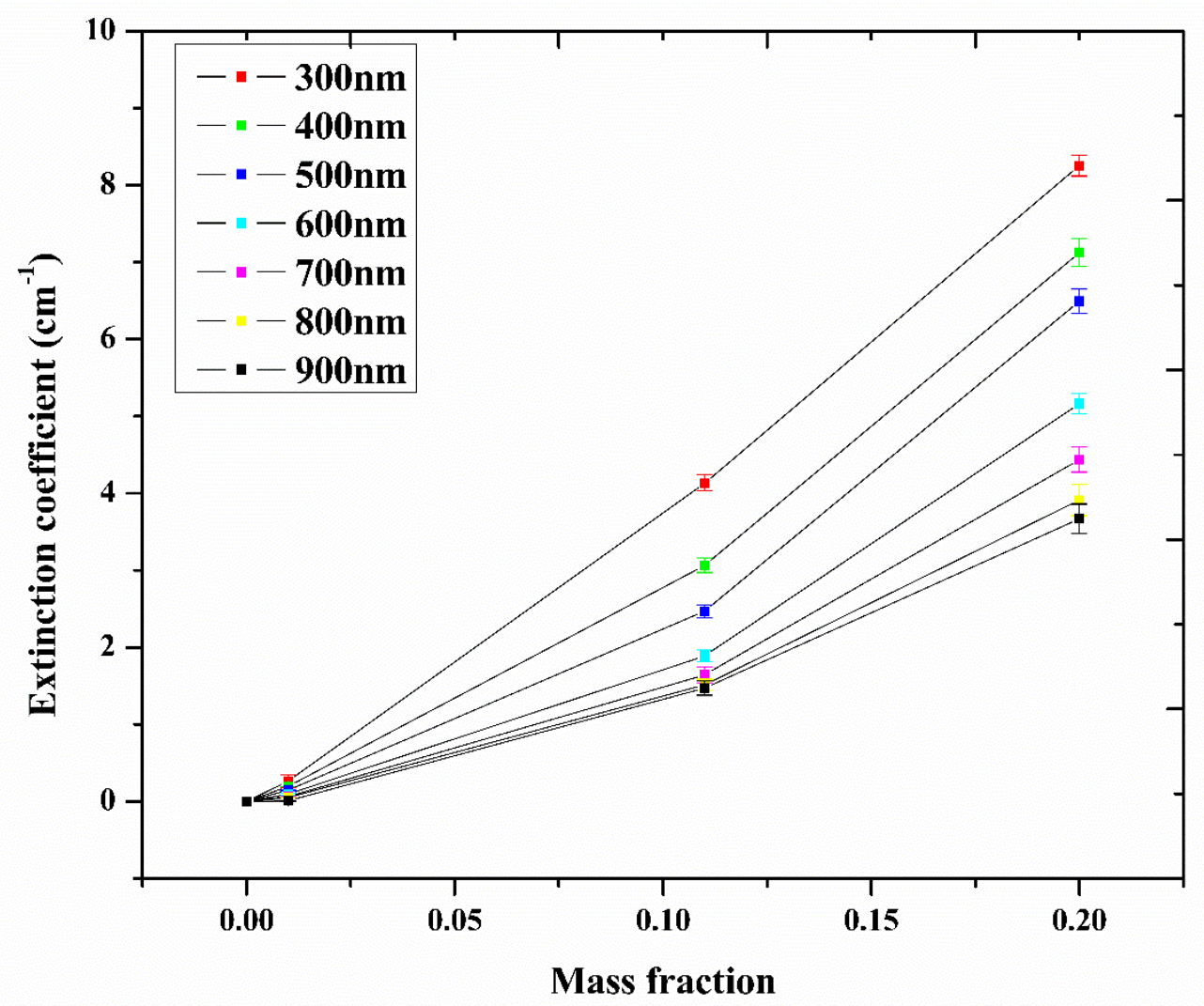

331

332

Fig. 9. Variation of extinction coefficient with mass fractions of nanoparticle 


\section{Optimization of mass fraction using Response surface methodology}

334 5.1. ANOVA analysis of Solar Weighted Absorption Fraction

335 Analysis of variance (ANOVA) of the solar weighted absorption fraction is presented in Table 3, 336 which provides information on the significant parameters in the designed model. The model is 337 significant as the p-value is less than 0.0001. $\mathrm{A}, \mathrm{B}, \mathrm{A}^{2,}$ and $\mathrm{AB}^{2}$ are the significant model terms as 338 their p-value is less than 0.1. ATO/Ag nanoparticle concentration is the most significant 339 independent parameter among the factors since it is having the highest $\mathrm{F}$ value. The lack of fit 340 being insignificant indicates that the model obtained is a correct fit. The difference between 341 predicted R-squared and adjusted R-squared being less than 0.2, as shown in Table 6, implies the 342 terms are in agreement. Furthermore, the value of R-squared and adjusted R-squared which are 3430.9839 and 0.9678 respectively, implies the model is fitting perfectly. Adequate-precision, which 344 measures the signal to noise ratio, is greater than the desired value of 4 . The coefficient of 345 determination (R-squared) value obtained was found to be greater than the good-fitting criterion 346 of 0.8 . Finally, the standard deviation of 2.16 points out the accuracy of the experiments.

Table 3: ANOVA of solar weighted absorption fraction

\begin{tabular}{ccccccc}
\hline Source & $\begin{array}{c}\text { Sum of } \\
\text { Squares }\end{array}$ & Df & $\begin{array}{c}\text { Mean } \\
\text { Square }\end{array}$ & $\begin{array}{c}\text { F } \\
\text { Value }\end{array}$ & $\begin{array}{c}\text { p-value } \\
\text { Prob }>\text { F }\end{array}$ & Significance \\
\hline Model & 1709.55 & 6 & 284.93 & 61.07 & $<0.0001$ & Significant \\
A-ATO/Ag & 1051.11 & 1 & 1051.11 & 225.28 & $<0.0001$ & \\
B-Surfactant & 28.13 & 1 & 28.13 & 6.03 & 0.0494 & \\
AB & 6.89 & 1 & 6.89 & 1.48 & 0.2698 & \\
$\mathrm{~A}^{2}$ & 92.98 & 1 & 92.98 & 19.93 & 0.0043 & \\
$\mathrm{~B}^{2}$ & 25.49 & 1 & 25.49 & 5.46 & 0.0581 & \\
AB $^{2}$ & 52.89 & 1 & 52.89 & 11.34 & 0.0151 & \\
Residual & 28.00 & 6 & 4.67 & & & not \\
Lack of Fit & 19.54 & 2 & 9.77 & 4.63 & 0.0911 & significant \\
Pure Error & 8.45 & 4 & 2.11 & & & \\
Cor Total & 1737.55 & 12 & & & &
\end{tabular}




$\begin{array}{cccc}\text { Std. Dev. } & 2.16 & \mathrm{R}^{2} & 0.9839 \\ \text { Mean } & 83.06 & \text { Adjusted R }^{2} & 0.9678 \\ \text { C.V. \% } & 2.60 & \begin{array}{c}\text { Predicted R } \\ 2\end{array} & 0.8161 \\ \text { PRESS } & 319.55 & \begin{array}{c}\text { Adequate } \\ \text { Precision }\end{array} & 28.926\end{array}$

348 An empirical correlation for solar weighted absorption fraction which was obtained from the model 349 developed for predicting responses for each level of factors, is given by Eq. (3). The significance 350 of the various factors cannot be inferred from coefficients in the equation as they are scaled to the 351 appropriate unit. As observed from Fig. 10, the values of solar weighted absorption fraction 352 obtained from experimental data and model predicted values are in good agreement. The error was 353 observed to be falling within $\pm 2 \%$.
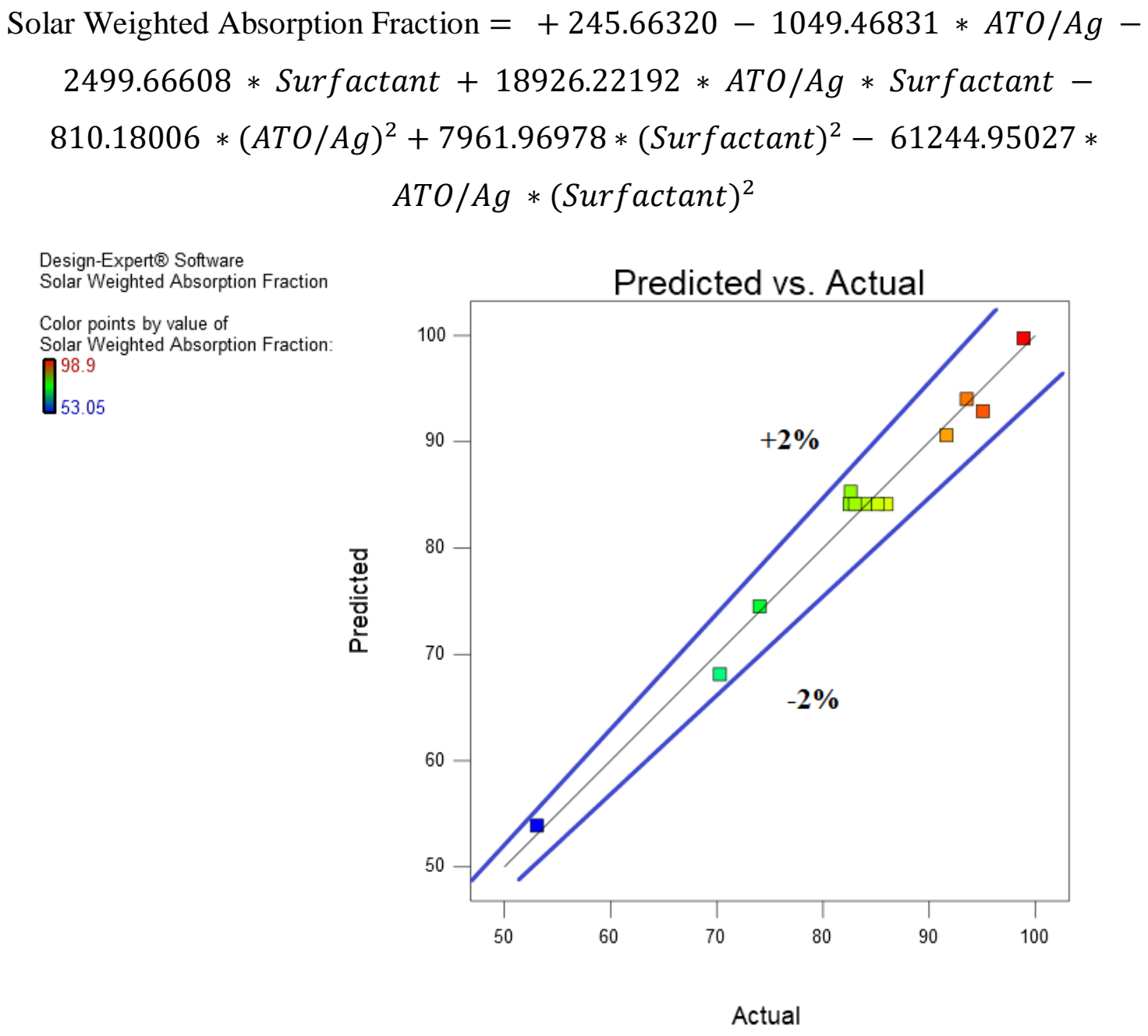

Fig. 10. Comparison between predicted values and actual values of $S_{m}$ 


\subsection{Interaction effect of process parameters on Solar weighted absorption fraction}

357 The 3D plot of absorption fraction with respect to ATO/Ag and SDS mass fraction, given by Fig.

358 11, clearly specifies that even though absorptivity increases with an increase in nanoparticle 359 concentration, the extreme surfactant concentration is seen to influence the absorption fraction. At minimum nanoparticle concentration, the absorption fraction is observed to be higher at the highest and the lowest surfactant concentration. The absorption fraction tends to increase with ATO/Ag nanoparticle concentration and then decreases at maximum nanoparticle concentration, for both high and low surfactant concentrations.

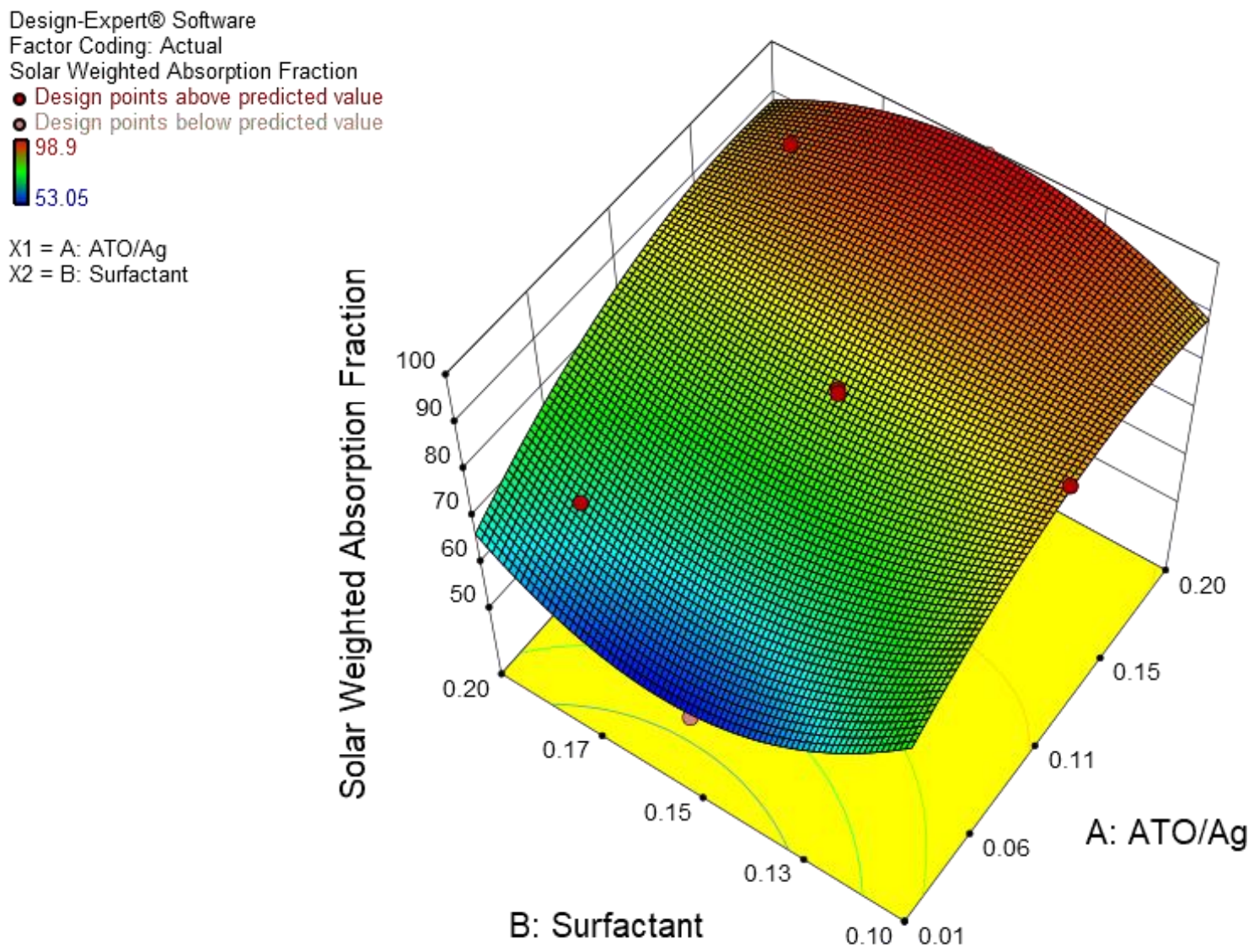

Fig. 11. Interaction effect of ATO/Ag and surfactant mass fractions on $S_{m}$ : 3D surface. influence on solar weighted absorption fraction. The maximum absorption fraction of $98.9 \%$ 
occurs at the highest concentration of nanofluid. For the samples Run 7 (0.17\% ATO/Ag - 0.19\%

370 SDS) and Run 10 (0.17\% ATO/Ag - 0.11\% SDS), having the same nanoparticle mass fractions,

371 the solar weighted absorption fraction was calculated to be $95 \%$ and $93.5 \%$ respectively. Hence

372 the effect of surfactant concentration on solar weighted absorption is minimal.

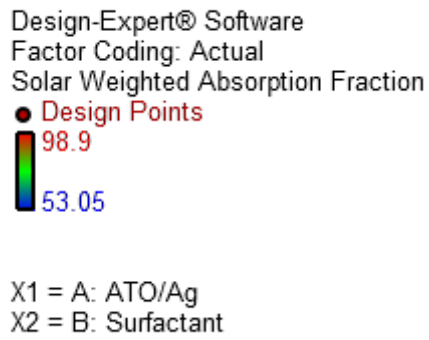

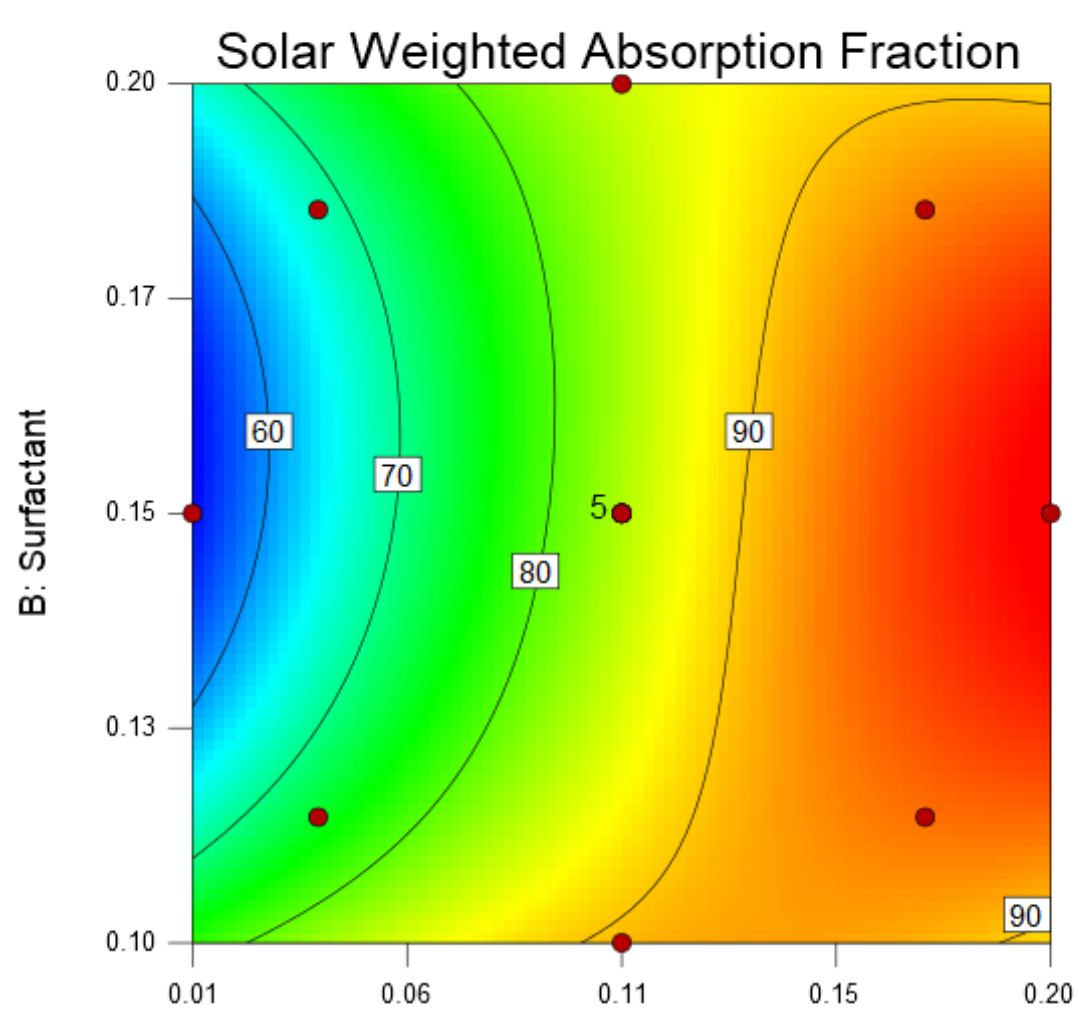

A: ATO/Ag

Fig. 12. Interaction effect of ATO/Ag and surfactant mass fractions on $S_{m}$ : contour plot.

375 As discussed in Section 3.2, since the enhancement in thermal conductivity by the addition of 376 nanoparticles was falling in the uncertainty range of the instrument, the optimization was 377 performed based on a single response variable i.e. solar weighted absorption fraction.

378 5.3. Optimization of variables using desirability function

379 The DOE model was created for statistically optimizing the response variables to obtain an optimum value of inputs. From the model developed, solar weighted absorption fraction at each 
factor levels are also obtained. Desirability is the objective function used for optimization. The weightage for variables can be adjusted on a scale of 1 to 5 [27, 34 and 35]. Increasing the weightage drives the output response towards the desired goal. Weightage of 3 was provided for solar weighted absorption fraction [35]. Desirability ranges from a minimum of zero to a maximum one. The maximum desirability provided by an operating condition is found by numerical optimization and was obtained as 0.532. The optimized concentrations of both ATO/Ag and SDS were obtained as $0.10 \%$. The solar weighted absorption fraction predicted for the optimized condition is $90.12 \%$. The weighted absorption fraction for the obtained optimum mass fraction was calculated experimentally and found to be $89 \%$ which is having a negligible error of $1.2 \%$ with the predicted value.

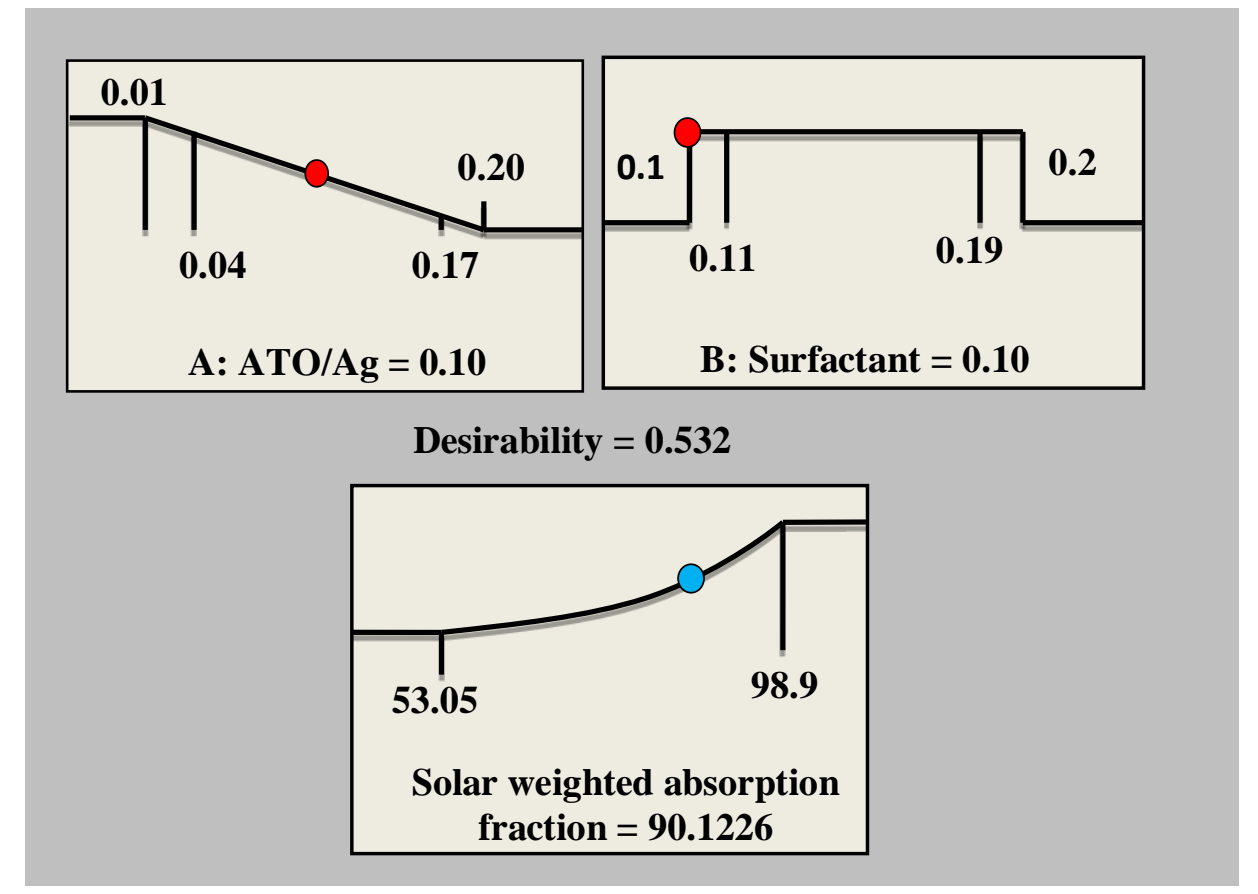

Fig. 13. Ramp function graph of desirability for numerical optimization

\subsection{Stability analysis of optimized nanofluid}

The sedimentation method was employed for investigating the stability of nanofluid [36] as shown in Fig. 14. On visual inspection, the ATO/Ag hybrid nanofluid was found to possess better stability compared to ATO nanofluid. The settling of ATO nanoparticles was prominent after 7 days from the synthesis date. Complete segregation of ATO nanoparticles was observed within 30 days after the synthesis. The optimized nanofluid $(0.1 \%$ ATO/Ag) and nanofluid sample with maximum 
399 concentration ( $0.2 \%$ ATO/Ag) exhibited better stability for 30 days with negligible segregation.

400 The optimized concentration was found to have achieved better dispersion stability compared to 401 nanofluid with $0.2 \%$ mass fraction for a longer time duration of 150 days.
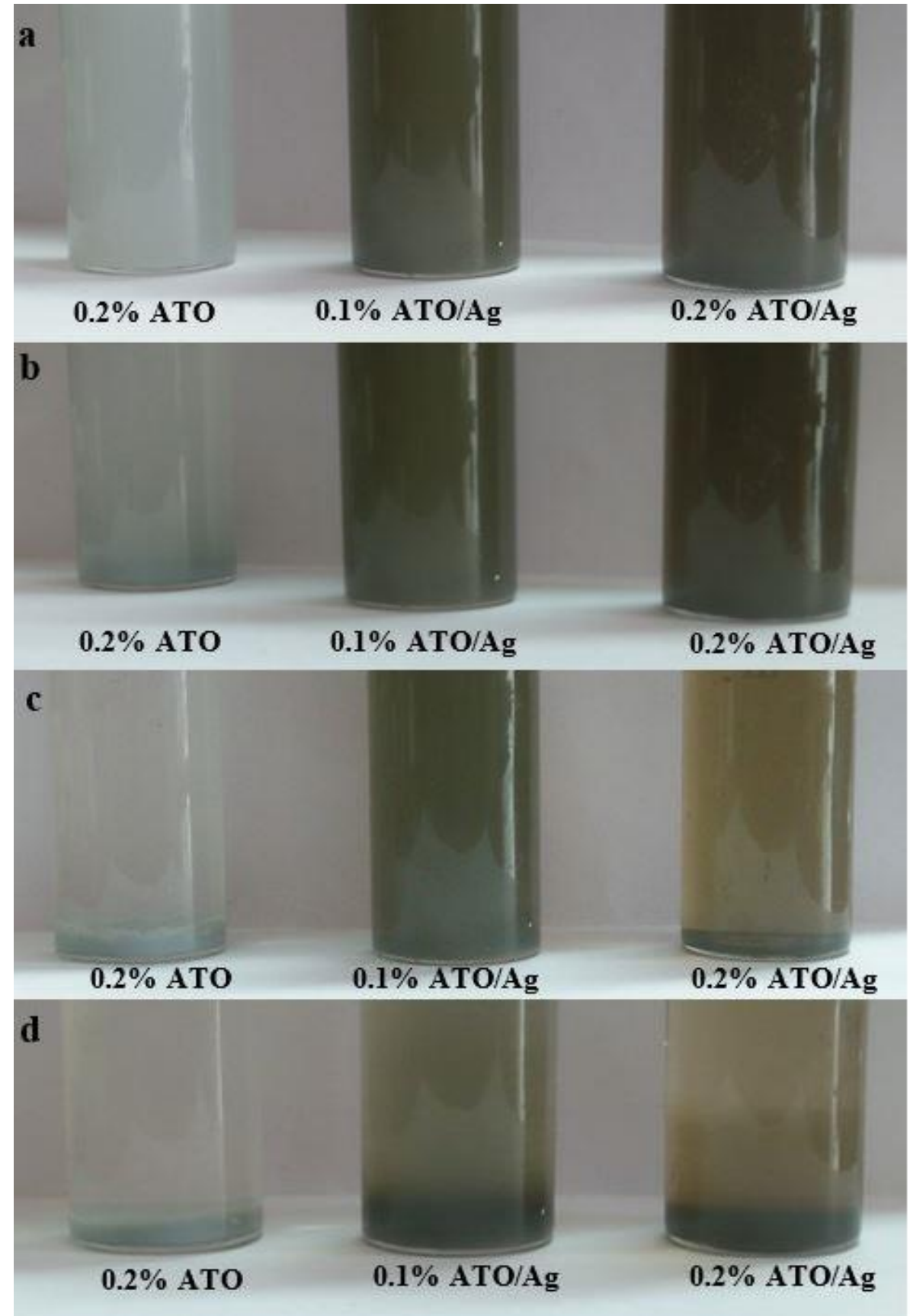

Fig. 14. Visual inspection on the stability of nanofluid after synthesis for a period of (a) 30

$$
\text { minutes (b) } 7 \text { days (c) } 30 \text { days (d) } 150 \text { days }
$$




\section{6. Experimentation on Parabolic trough direct absorption solar collector}

406 6.1. Reflector and absorber tube

407 The solar thermal collector system consists of a parabolic shaped reflector mirror, a glass cover 408 and a receiver tube placed at the focal point of the reflector. The focal point is at a distance of 0.27

$409 \mathrm{~m}$ from the vertex. The parabola and receiver dimensions are given in Table 5. The receiver tube

410 is a quartz tube with high optical transmittance. A glass cover was used for preventing the 411 convective heat loss from the receiver tube surface to the environment. The annular space is filled

412 with air and sealed at both ends to prevent the effect of wind. The working fluid is flowing inside 413 the receiver tube. Volumetric absorption of the concentrated solar rays occurs inside the fluid 414 volume in the receiver tube. The shape and focal point of parabolic reflectors are given by Eq. (4) 415 and Eq. (5) respectively.

$$
\begin{aligned}
& y=0.925 x^{2} \\
& f=\frac{W_{a}}{2} \cot \varphi_{r}+\frac{W_{a}^{2}}{16 f} \\
& \text { F } \quad \text { Focal distance (m) } \\
& \text { W } \quad \text { Aperture width (m) } \\
& \varphi \quad \text { Rim angle (degree) }
\end{aligned}
$$

Table 5: Dimensions of the receiver tube

\begin{tabular}{cc}
\hline \multicolumn{1}{c}{ Parameters } & Dimensions \\
\hline Absorber tube inner diameter & $15 \mathrm{~mm}$ \\
Absorber tube outer diameter & $18 \mathrm{~mm}$ \\
Glass cover inner diameter & $36 \mathrm{~mm}$ \\
Glass cover outer diameter & $40 \mathrm{~mm}$ \\
Length of the receiver tube & $1500 \mathrm{~mm}$ \\
Aperture width & $1080 \mathrm{~mm}$ \\
Focal point & $270 \mathrm{~mm}$ \\
\hline
\end{tabular}


418 The hydraulic cycle of the collector system was based on ASHRAE Standard 93-2010 as shown 419 in Fig. 15. The fluid flow is controlled using the main valve and a bypass valve. The bypass valve 420 was installed for the low flow rates according to the ASHRAE standards. The concentrated solar 421 radiation is absorbed by the nanofluid while passing through the receiver tube. The temperatures 422 at the inlet and exit were measured using calibrated T-type thermocouples with an accuracy of 0.5 $423{ }^{\circ}$ C. Rotameter present at the flow outlet will measure the fluid flow rate through the cycle. The 424 absorbing fluid enters the heat exchanger to reject heat and is pumped back through the cycle.

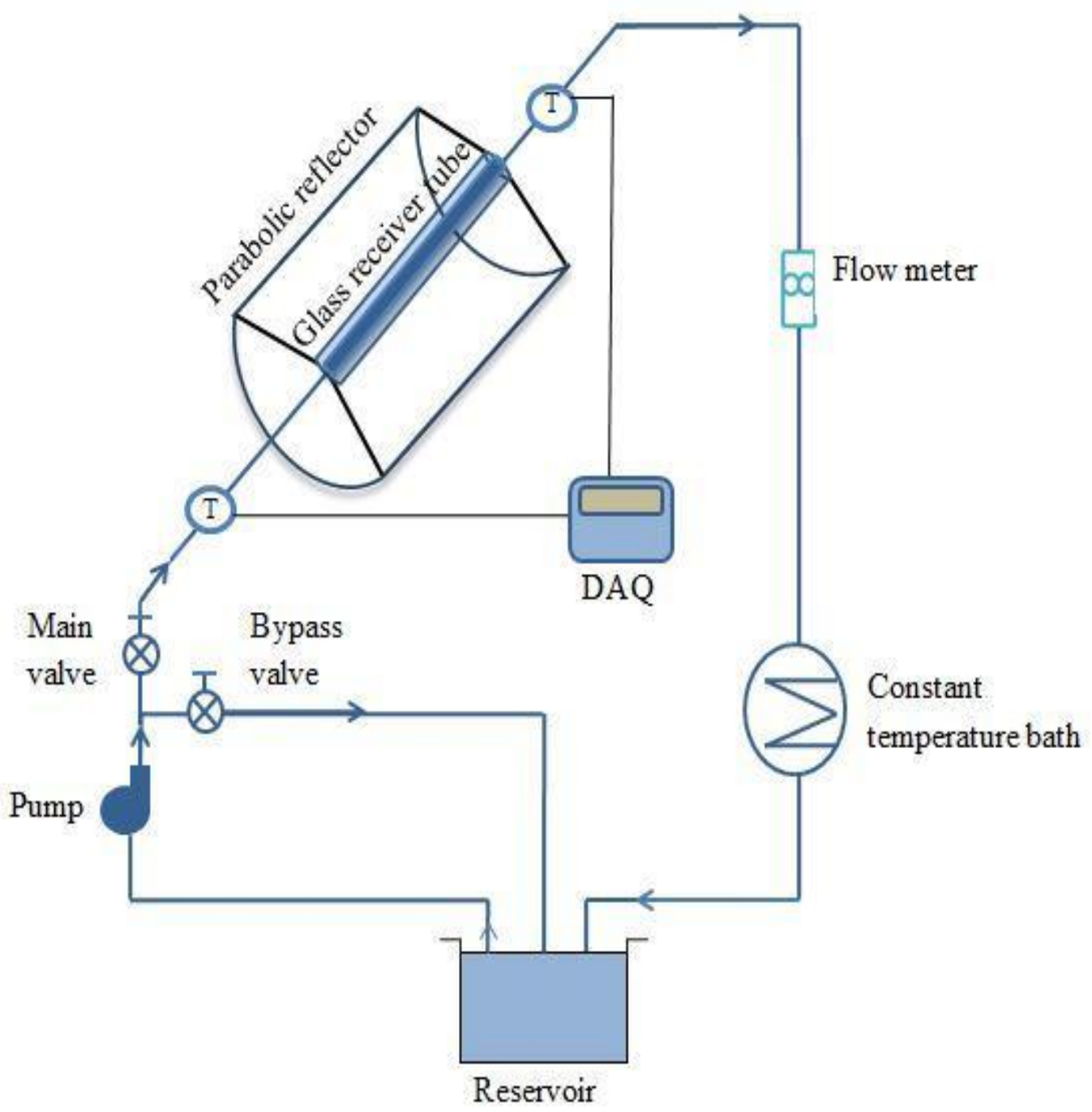

Fig. 15. The schematic of the hydraulic cycle 
428 The actual experimental setup is shown in Fig. 16. A single-axis solar tracking was performed for 429 the experiment. The automated solar tracker aligns the position of the reflector directly towards 430 the radiation. The incidence angle is having a predominant effect on the thermal efficiency of the 431 collector [37]. Hence, after experimenting on a range of incidence angles between $0^{\circ}$ and $20^{\circ}$, the 432 inclination equal to the incidence angle $\left(11.3^{\circ}\right)$ was found to be providing higher efficiency. 433 Providing an inclination equal to the incidence angle, will decrease the shadowing at the ends and 434 allows direct solar irradiation. The solar intensity was measured using an industrial standard 435 pyranometer with an accuracy of $\pm 5 \mathrm{~W}^{-2}$.

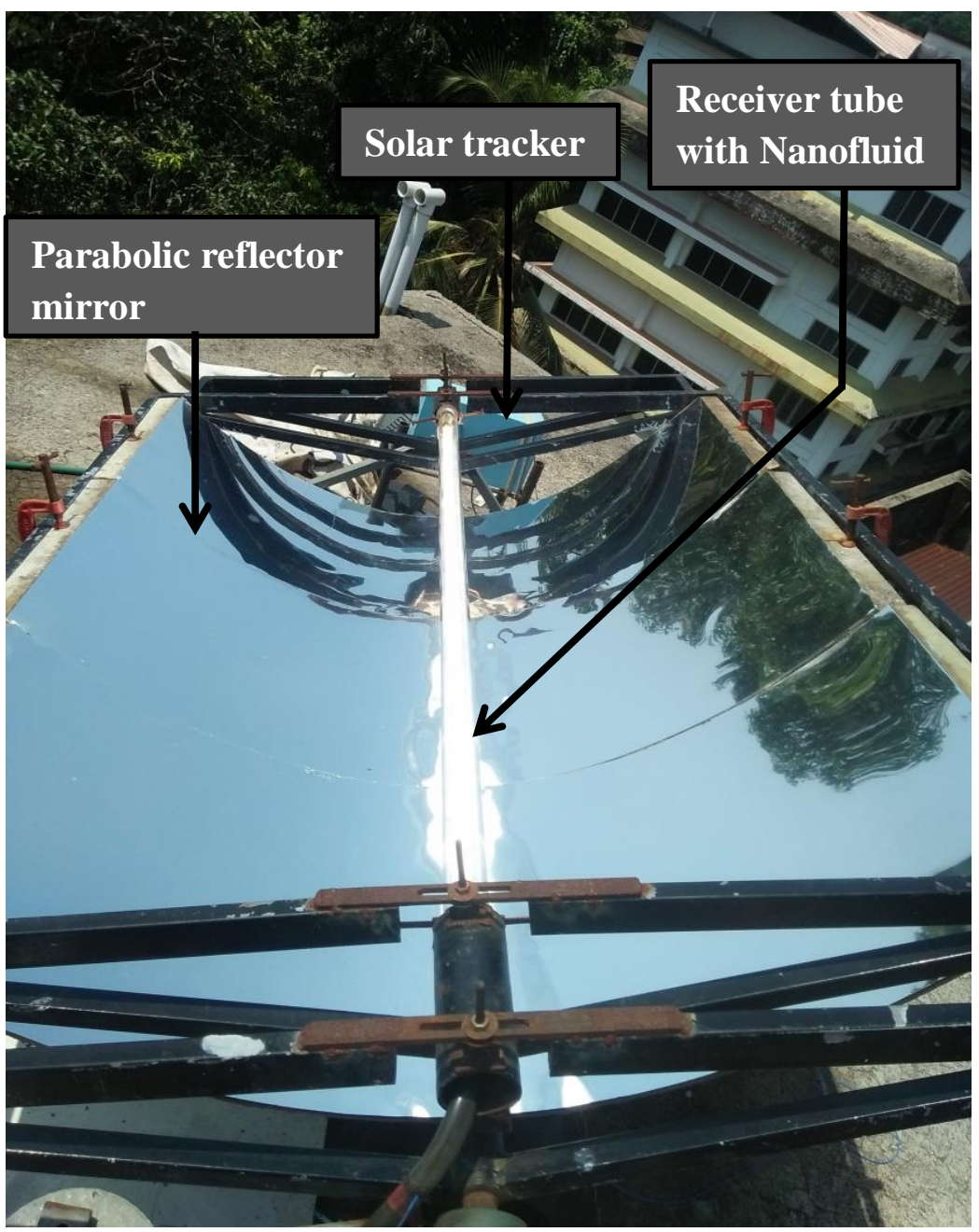




\subsubsection{Thermal efficiency}

443 Instantaneous thermal efficiency was calculated at a time step of 5 minutes during the test day.

444 Thermal efficiency calculated using Eq. (6), is the ratio between useful thermal energy of nanofluid 445 to the total energy received by the parabolic trough collector.

$$
\eta_{t h}=\frac{\dot{m} C_{p, h} \Delta T}{I A}
$$

446

447

448

449

450

451

453

455

452 the reflector. A MATLAB code was generated to solve Eq. (9) using Simpson's one-third rule, to

454 were used to find the optical efficiency at each incidence angle using Eq. (7). The Intercept factor

\subsubsection{Optical efficiency}

The optical efficiency of the collector is obtained by considering all the optical materials that are occurring in the path of the light beam. Geometric and intercept factors need to be found out for calculating the optical efficiency using Eq. (7) [38]. Geometric factor, K, given by Eq. (8), is a measure of the effective reduction of the aperture area due to abnormal incidence effects. The intercept factor, $\gamma$, is the ratio of the energy intercepted by the receiver to the energy reflected by

53 find the intercept factor. Geometric factor, intercept factors, and solar collector material properties 55 [39] was found to be 0.9228 from Eq. (9).

$$
\begin{gathered}
\eta_{\text {optical }}=\left(\rho_{\text {collector }} \tau_{\text {cover }} \alpha_{\text {receiver }}\right) * \gamma *\left(1-A_{f} \tan \theta\right) \cos \theta \\
K=1-\left(\frac{D_{\text {out }}}{L_{a}}+\frac{f}{L_{a}}\left(1+\frac{W_{a}^{2}}{48 L_{a}^{2}}\right)\right) \tan \theta \\
\gamma=\frac{1+\cos \varphi_{r}}{2 \sin \varphi_{r}} \int_{0}^{\theta_{r}} \operatorname{erf}\left(\frac{\sin \varphi_{r}(1+\cos \theta)(1-2 d \sin \theta)-\left(\pi \beta\left(1+\cos \varphi_{r}\right)\right)}{\sqrt{2} \pi \sigma\left(1+\cos \varphi_{r}\right)}\right)+ \\
-\operatorname{erf}\left(-\frac{\sin \varphi_{r}(1+\cos \theta)(1+2 d \sin \theta)+\left(\pi \beta\left(1+\cos \varphi_{r}\right)\right.}{\sqrt{2} \pi \sigma\left(1+\cos \varphi_{r}\right)}\right) \frac{d \theta}{1+\cos \theta}
\end{gathered}
$$


457 Exergy is defined as the maximum useful work that can be extracted from a system at a given state 458 in a specific environment. Exergy analysis is crucial in analyzing the potential of solar thermal 459 systems.

460 Assumptions for exergy analysis:

1. Kinetic and potential energies are neglected

2. Chemical and nuclear interactions are neglected

465 Based on the assumptions stated above, an exergy balance across the receiver was formulated as 466 shown in the Eq. (10-15). The exergy efficiency of the PTDASC is given by Eq. (15). Exergy from 467 solar radiation and fluid flow are the significant contributing factors in the exergy balance of the 468 concerned PTDASC.

$$
\begin{gathered}
\Sigma \psi_{\text {in }}-\Sigma \psi_{\text {out }}=\psi_{\text {dest }} \\
\psi_{\text {sol }}+\psi_{m, \text { in }}-\psi_{m, \text { out }}=\psi_{\text {dest }}
\end{gathered}
$$

469 Where the $\psi_{m, \text { in }}$ and $\psi_{m, o u t}$ are calculated by using Eq. 12 and Eq. 13 respectively.

$$
\begin{gathered}
\psi_{m, \text { in }}=\left(h_{\text {in }}-h_{a m b}\right)-T_{a m b}\left(s_{\text {in }}-S_{a m b}\right) \\
\psi_{m, \text { out }}=\left(h_{\text {out }}-h_{a m b}\right)-T_{a m b}\left(s_{\text {out }}-S_{a m b}\right)
\end{gathered}
$$

470 Incident solar power received by the parabolic collector is obtained by multiplying the collector 471 aperture area with instantaneous solar radiation intensity as given by Eq. (14).

$$
Q_{\text {sol }}=I A
$$


472 Parabolic trough utilizes only beam radiation which can be assumed to be undiluted. Petela's

473 exergy efficiency model [40] was used for finding the maximum power available from the incident

474 solar radiation. The Sun was taken as the radiation reservoir which is having a temperature of 475 5770K. The maximum work potential from solar radiation is calculated by multiplying the solar 476 exergy efficiency with incident solar power, as shown in Eq. (15).

$$
\psi_{s o l}=\left(1-\frac{4 T_{a m b}}{3 T_{s}}+\frac{1}{3}\left(\frac{T_{a m b}}{T_{S}}\right)^{4}\right) * I A
$$

477 The Eq. (16), as described below, is obtained by substituting Eqs. (12), (13) and (15) in Eq. (11).

$$
\psi_{\text {dest }}=\psi_{\text {sol }}-\dot{m} C_{p}\left(\left(T_{\text {out }}-T_{\text {in }}\right)-T_{\text {amb }} \ln \left(\frac{T_{\text {out }}}{T_{\text {in }}}\right)\right)+\frac{m T_{\text {amb }} \Delta P}{\rho T_{\text {fm }}}
$$

478 The irreversibility term due to pressure drop in Eq. (16) can be ignored as the effect is less 479 significant [41]. The higher density of liquid working fluids, compared to gaseous ones, account 480 for the fact that irreversibility due to pressure drop in parabolic trough collector can be neglected 481 while using liquid working fluids [42]. The exergy efficiency of the system is calculated using 482 Eqn. (17).

$$
\eta_{\text {ex }}=1-\left(\frac{\psi_{\text {dest }}}{\psi_{\text {sol }}}\right)
$$

\subsubsection{Uncertainty analysis}

484 The uncertainty analysis was performed for quantifying the accuracy of the measurements. Error 485 analysis was conducted to find the errors associated with the thermal efficiency and exergy efficiency. Uncertainties for thermal efficiency and exergy efficiency were calculated using the Moffat method [43] as described in Eq. 18 and Eq. 19 respectively. The uncertainty associated with measurement of temperature, incident solar radiation, and the flow rate is $\pm 1.4 \%, \pm 0.625 \%$ and $\pm 2.5 \%$, respectively. The precision error occurring during the measurement of the extinction coefficient was taken into consideration and overall uncertainty in the measurement of the extinction coefficient was calculated to be $\pm 0.8 \%$. The mean uncertainty involved in the 
calculation of the dependent parameters, thermal and exergy efficiency, was found to be $\pm 2.2 \%$ and $\pm 1.5 \%$ respectively.

$$
\begin{gathered}
\frac{\delta \eta_{\text {th }}}{\eta_{\text {th }}}=\sqrt{\left(\frac{\delta m}{m}\right)^{2}+\left(\frac{\delta \Delta T_{\text {in }}}{\Delta T_{\text {in }}}\right)^{2}+\left(\frac{\delta \Delta T_{\text {out }}}{\Delta T_{\text {out }}}\right)^{2}+\left(\frac{\delta I}{\Delta I}\right)^{2}} \\
\frac{\delta \eta_{\text {ex }}}{\eta_{\text {ex }}}=\sqrt{\left(\frac{\delta m}{m}\right)^{2}+\left(\frac{\delta \Delta T_{\text {in }}}{\Delta T_{\text {in }}}\right)^{2}+\left(\frac{\delta \Delta T_{\text {out }}}{\Delta T_{\text {out }}}\right)^{2}+\left(\frac{\delta T_{\text {amb }}}{T_{\text {amb }}}\right)^{2}+\left(\frac{\delta I}{I}\right)^{2}}
\end{gathered}
$$

\subsection{Energy and Exergy analysis}

From Fig. 17, it is observed that the maximum optical efficiency of $75 \%$ is obtained when direct solar radiation is received at zero incidence angles. The various results of experimentation performed on nanofluid applied PTDASC at different flow rates are shown in Figs. 18, 19 and 20. The Figs. 18, 19 and 20 (c) illustrates the solar irradiation data received on each test day. The scattering observed in the energy and exergy efficiency curves in Figs. 18 and 19 (b) can be attributed to the thermal inertia during volumetric absorption. The variation in the solar irradiation received by the parabolic trough collector will affect the outlet temperature of the nanofluid which in turn produces the fluctuation in efficiency curves $[44,45]$. The efficiency curve at the highest flow rate, Fig. 18 (b), shows that almost $90 \%$ of the data points corresponding to the instantaneous thermal efficiency of the solar collector was falling within a range of $40 \%$ to $60 \%$. In the case of lower flow rates, the thermal efficiencies were varying in a smaller range which showed consistent results. The variation of instantaneous thermal and exergy efficiency with time for base fluid with flow rates of $0.016,0.019$ and $0.022 \mathrm{kgs}^{-1}$ is shown in Fig. 21 (a), (b) and (c) respectively. The variation in thermal and exergy efficiency of the hybrid nanofluid applied DASC with temperature difference across the receiver length was plotted for three different mass flow rates. The graphs Figs. 18, 19 and 20 (b), throws light on the dependence of efficiencies on the temperature difference attained. As observed in Fig. 18 (b), the thermal efficiency was increasing linearly with the rise in temperature difference across the tube length. Even though the exergy efficiency exhibited almost a similar trend as that of thermal efficiency, the highest exergy and thermal efficiencies were not occurring for the same nanofluid temperature gain. The highest exergy efficiency corresponded to the achievement of $8^{\circ} \mathrm{C}$ difference in nanofluid temperature across the system, while the peak thermal efficiency was pertaining to a rise of $12.6{ }^{\circ} \mathrm{C}$. Also, in the case of 
517 Fig. 19 and 20 (b), the trendlines of the efficiencies were almost parallel. The temperature 518 difference between the inlet and outlet of the receiver was observed to increase with a decrease in 519 the flow rate of the working fluids. The outlet temperature of the nanofluid increased by $3{ }^{\circ} \mathrm{C}$ when 520 the flow rate was decreased from $0.022 \mathrm{kgs}^{-1}$ to $0.016 \mathrm{kgs}^{-1}$.

521 From the experimental data obtained, the variation of thermal and exergy efficiency with solar 522 irradiation is plotted as shown in Fig. 22. Thermal and exergy efficiency was observed to increase 523 with the increase in solar irradiance. A decrease in the exergy efficiency was noticed with an 524 increase in solar irradiance above $800 \mathrm{Wm}^{-2}$ while thermal efficiency was observed to increase. It 525 could be concluded that higher solar flux can produce more heat loss from the system. The effect 526 of heat loss on the exergy efficiency is higher compared to that of energy efficiency. Incident solar 527 irradiation was found to be having a predominant effect on the thermal efficiency enhancement 528 when compared with exergy efficiency. The variation of thermal and exergy efficiency of the 529 530 collector with flow rates is shown in Fig. 23. It is observed that the maximum efficiency of the collector was pertaining to the maximum flow rate. The highest thermal efficiency and exergy 531 efficiency observed was $63.5 \%$ and $5.6 \%$ respectively at a flow rate of $0.022 \mathrm{kgs}^{-1}$. As the flow 532 rate increased from $0.016 \mathrm{kgs}^{-1}$ to $0.019 \mathrm{kgs}^{-1}$ and $0.022 \mathrm{kgs}^{-1}$, the thermal efficiency increased by $533 \quad 3.1 \%$ and $5.3 \%$ respectively, and the corresponding increase in exergy efficiency was $11.8 \%$ and $53417.68 \%$, respectively. The substantial rise in the exergy efficiency when compared to thermal 535 efficiency shows that the former is more dependent on solar irradiation while the latter is easily 536 controlled by flow rate. Hence optimization of the working parameters is required for the 537 collector's efficient performance. Exergy efficiency is dependent on the fluid inlet and outlet 538 temperatures, incident solar radiation and the ambient temperature. As the flow rate increases the 539 loss of heat from the collector is reduced as the time spent by nanofluid in the receiver is less. 540 Hence an increase in thermal and exergy efficiency will be observed. Also, the maximum nanofluid 541 outlet temperature increased with a decrease in flow rate. As the flow rate decreased, more energy conversion took place due to absorption and scattering.

543 If the ambient temperature of the surrounding is high, then the exergy efficiency will be high 544 compared to the same conditions at lower ambient conditions. So, as the exergy varies due to more 545 factors compared to thermal efficiency, a linear relationship between these efficiencies could not 
546 be stated from the results obtained. Also, the exergy efficiency is only important at inferring the 547 necessary heat loss reducing methods and not a factor at evaluating the applicability of the system.

548

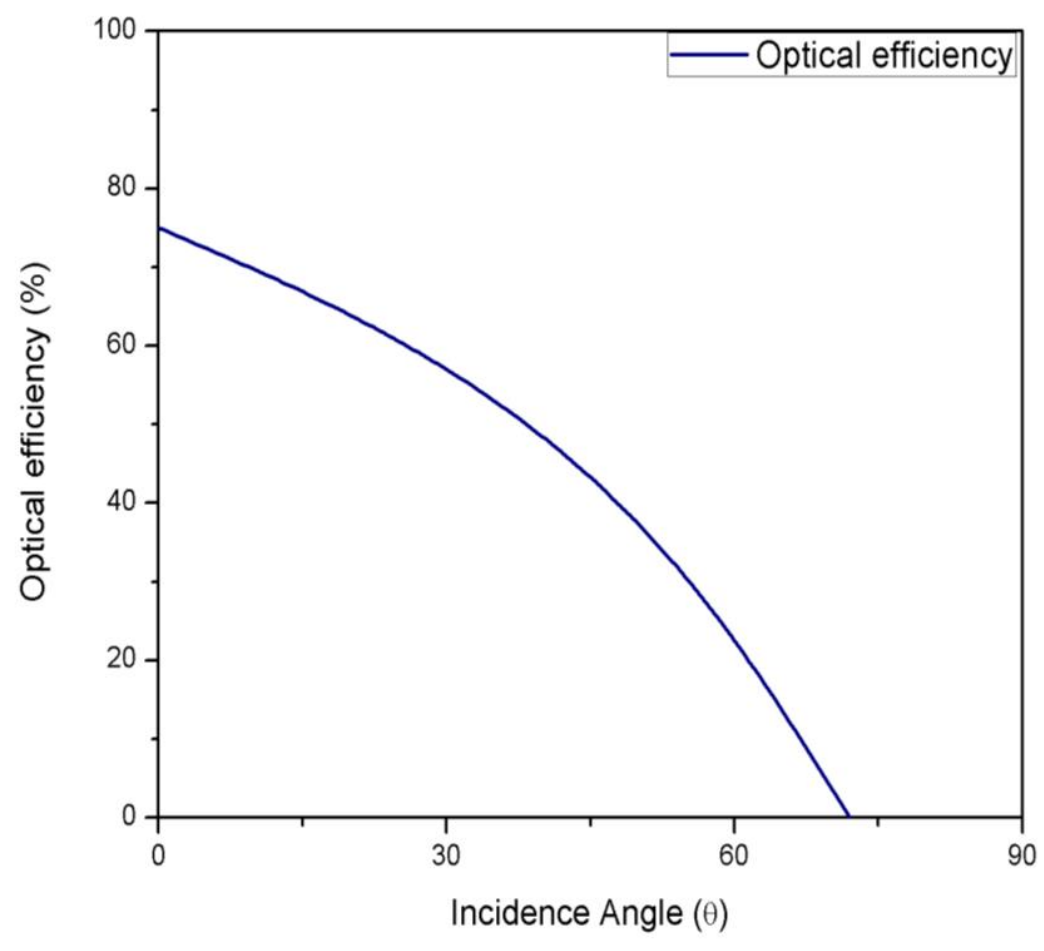

549

Fig. 17. Variation of optical efficiency with incidence angle 

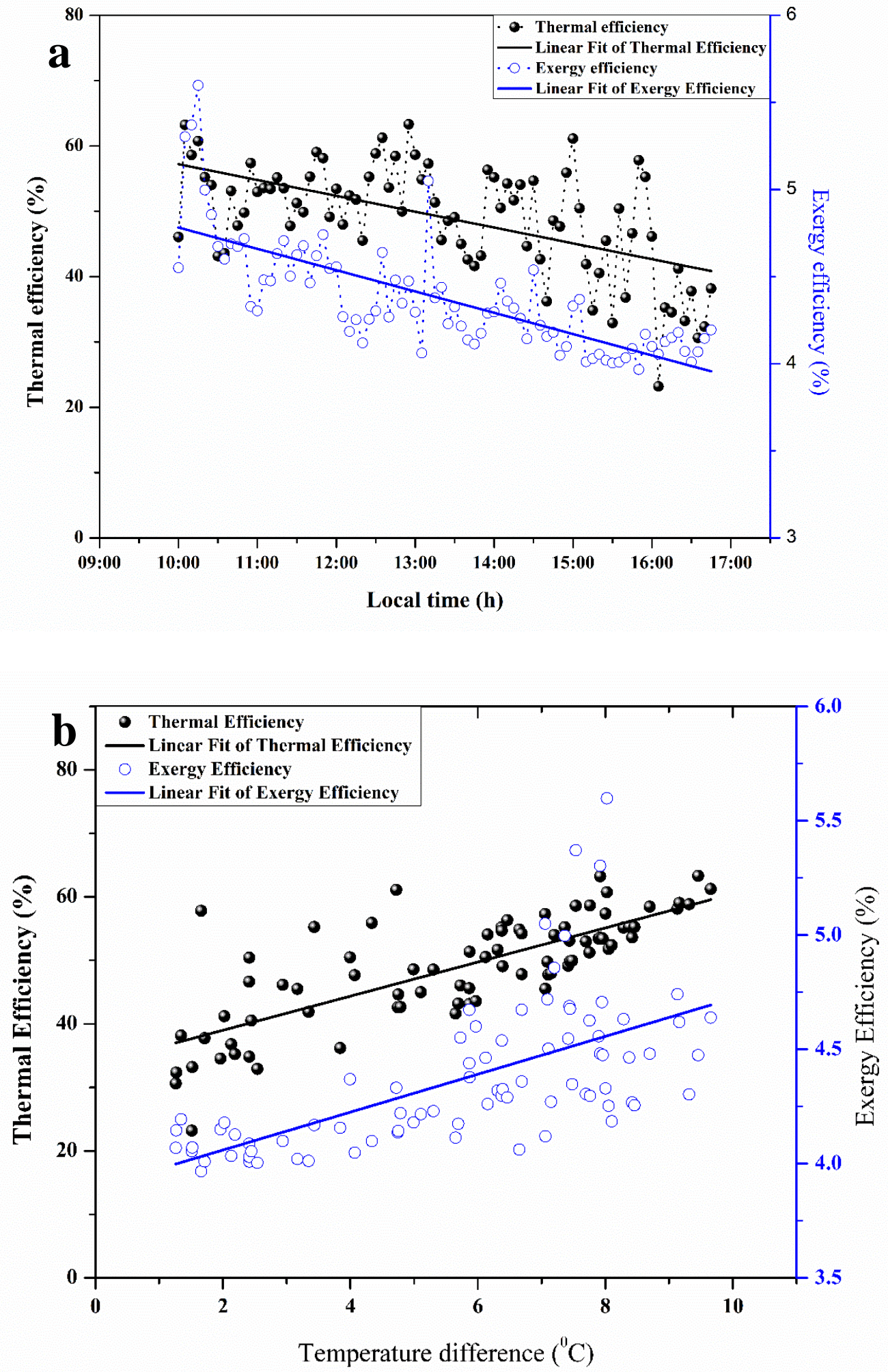


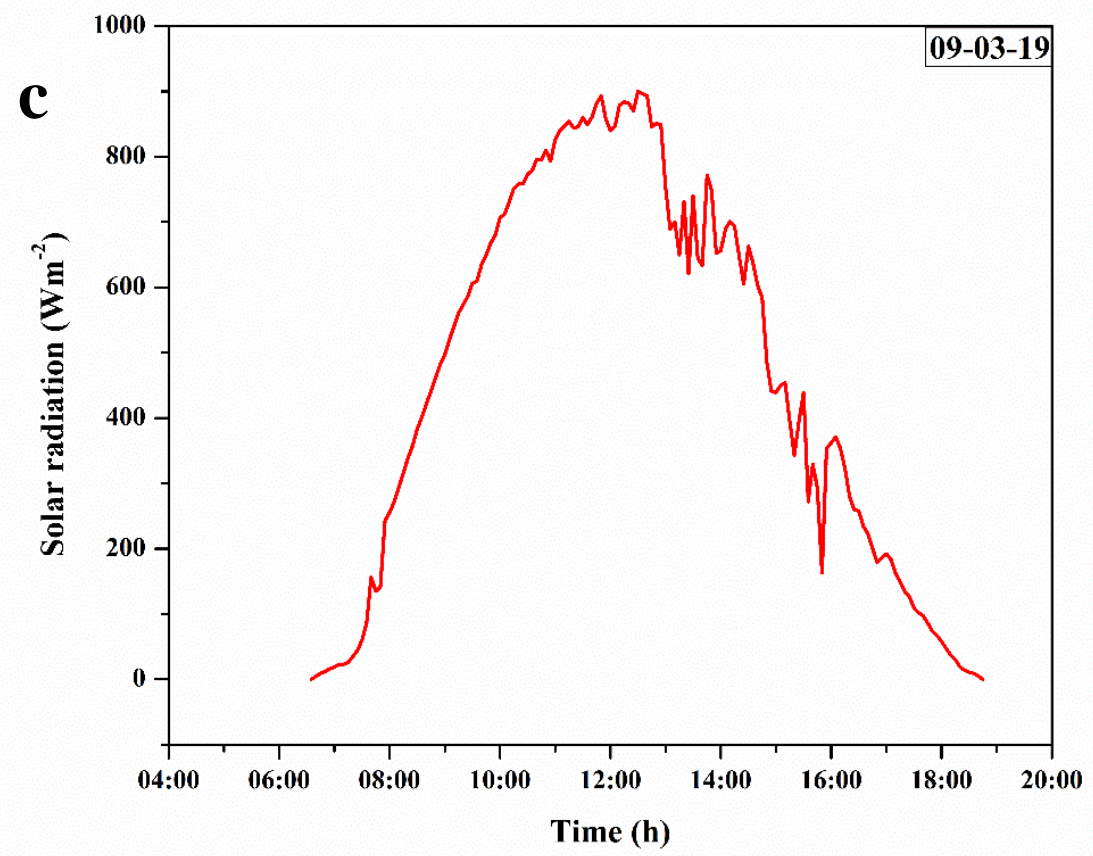

554

555 Fig. 18. (a) Thermal and exergy efficiency of PTDASC at $0.022 \mathrm{kgs}^{-1}$, (b) Variation of thermal 556 and exergy efficiency with temperature difference (c) Solar radiation data for 09-03-19

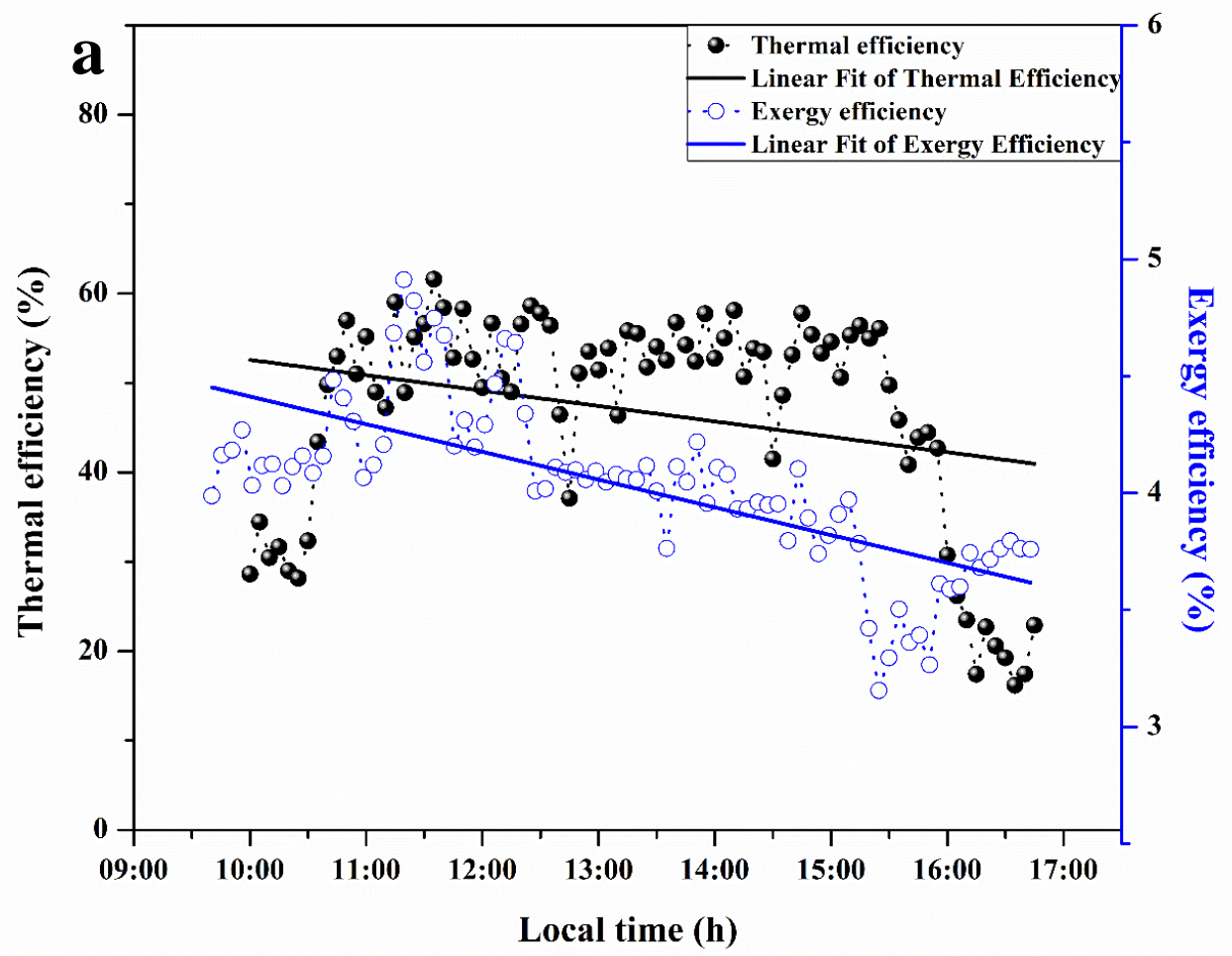



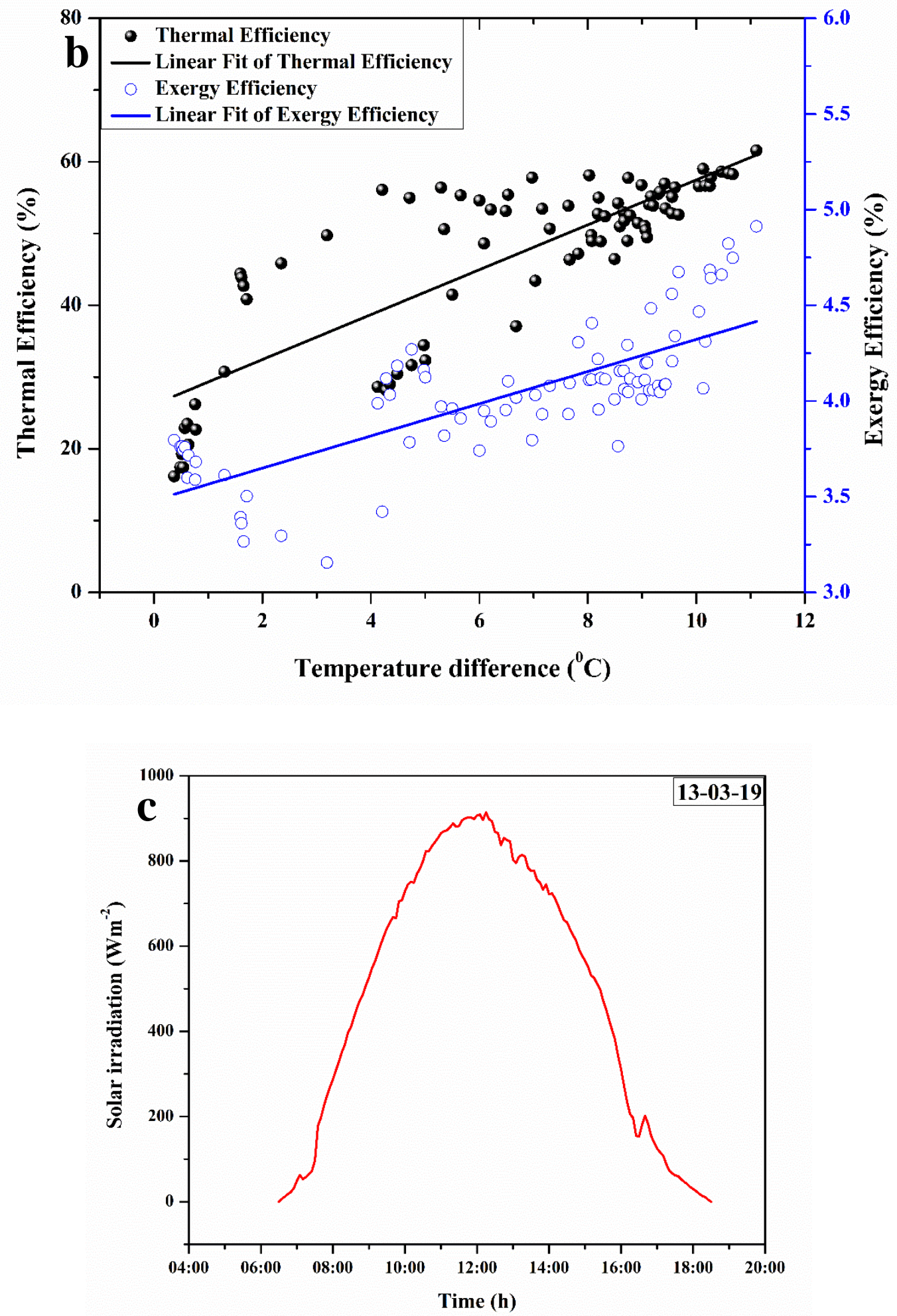

560 Fig. 19. (a) Thermal and exergy efficiency of PTDASC at $0.019 \mathrm{kgs}^{-1}$, (b) Variation of thermal and exergy efficiency with temperature difference (c) Solar radiation data for 13-03-19 

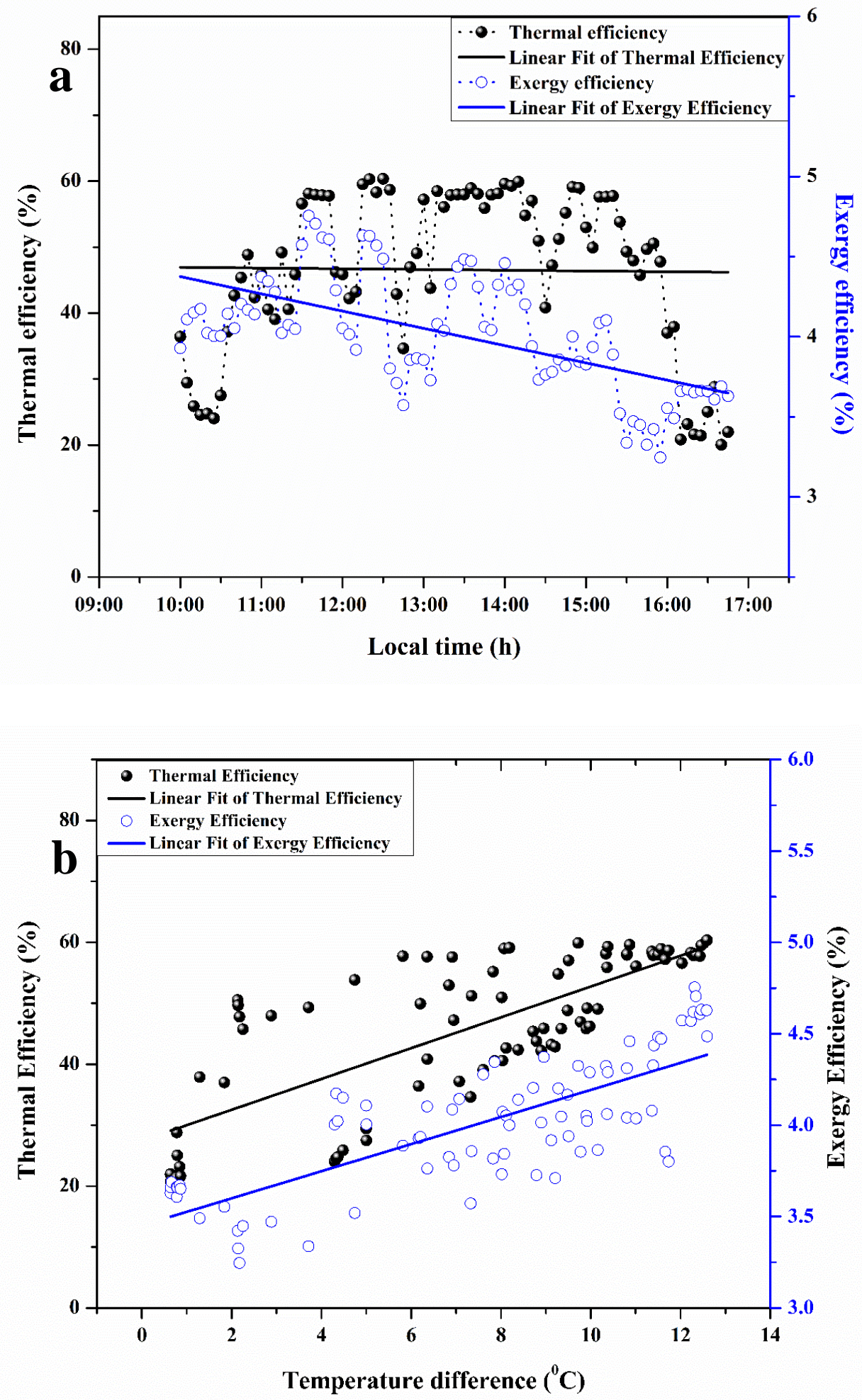


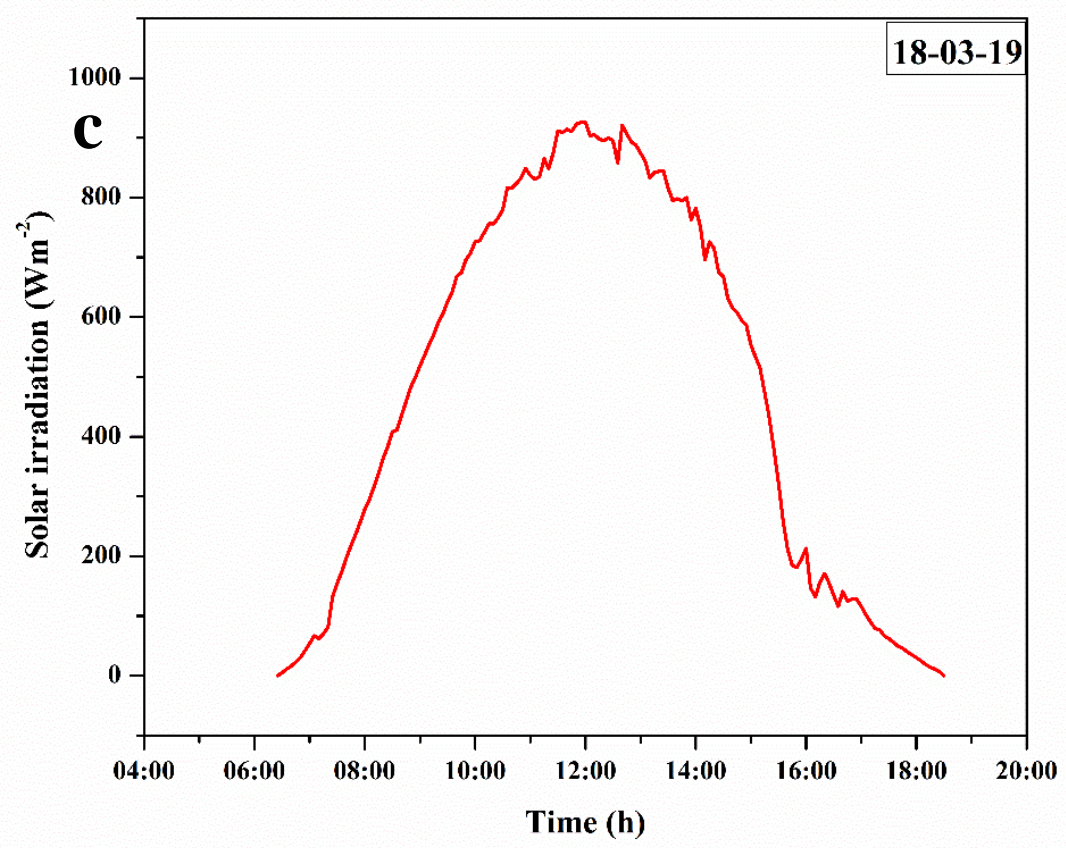

565 Fig. 20. (a) Thermal and exergy efficiency of PTDASCC at $0.016 \mathrm{kgs}^{-1}$, (b) Variation of thermal and exergy efficiency with temperature difference (c) Solar radiation data for 18-03-19

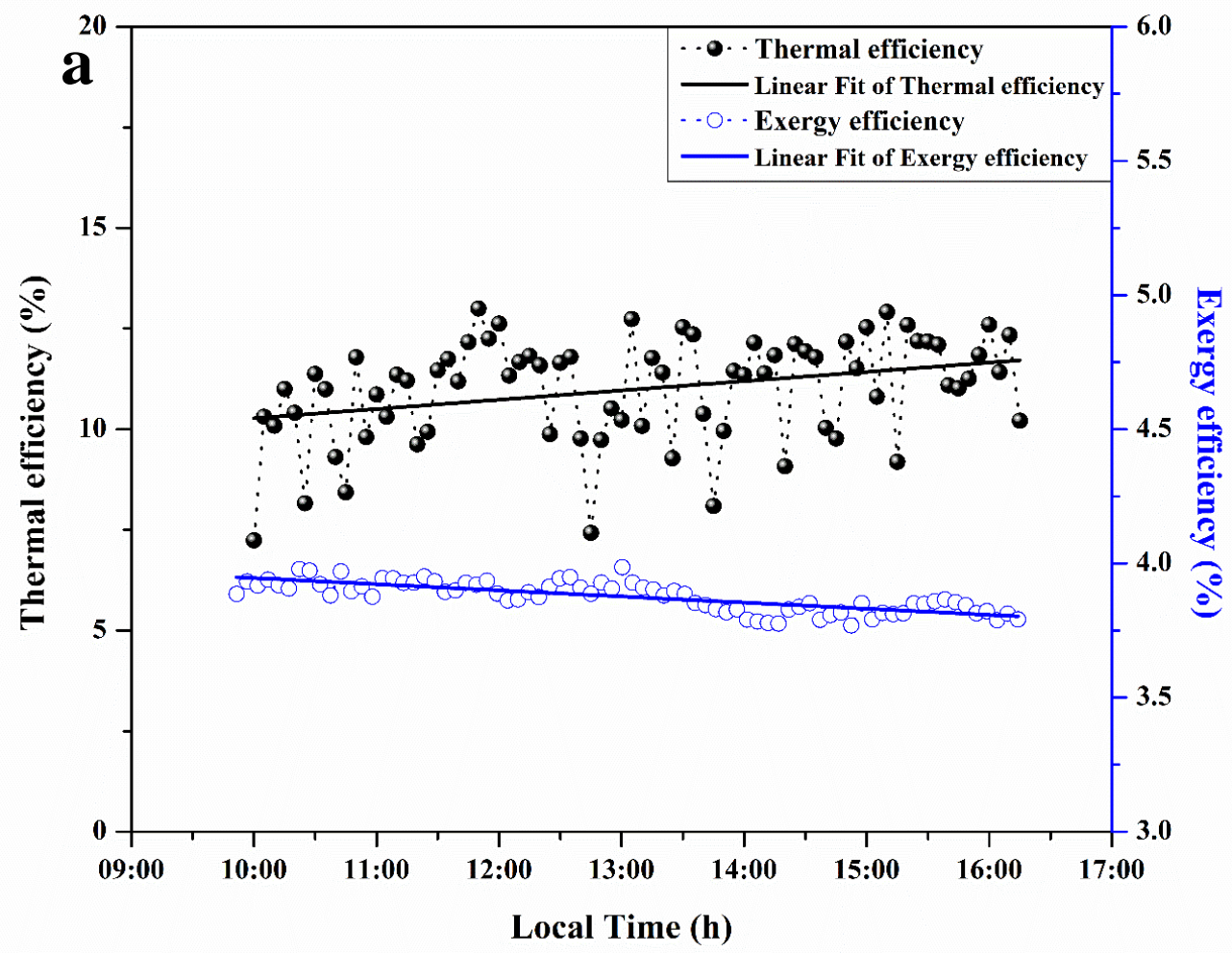



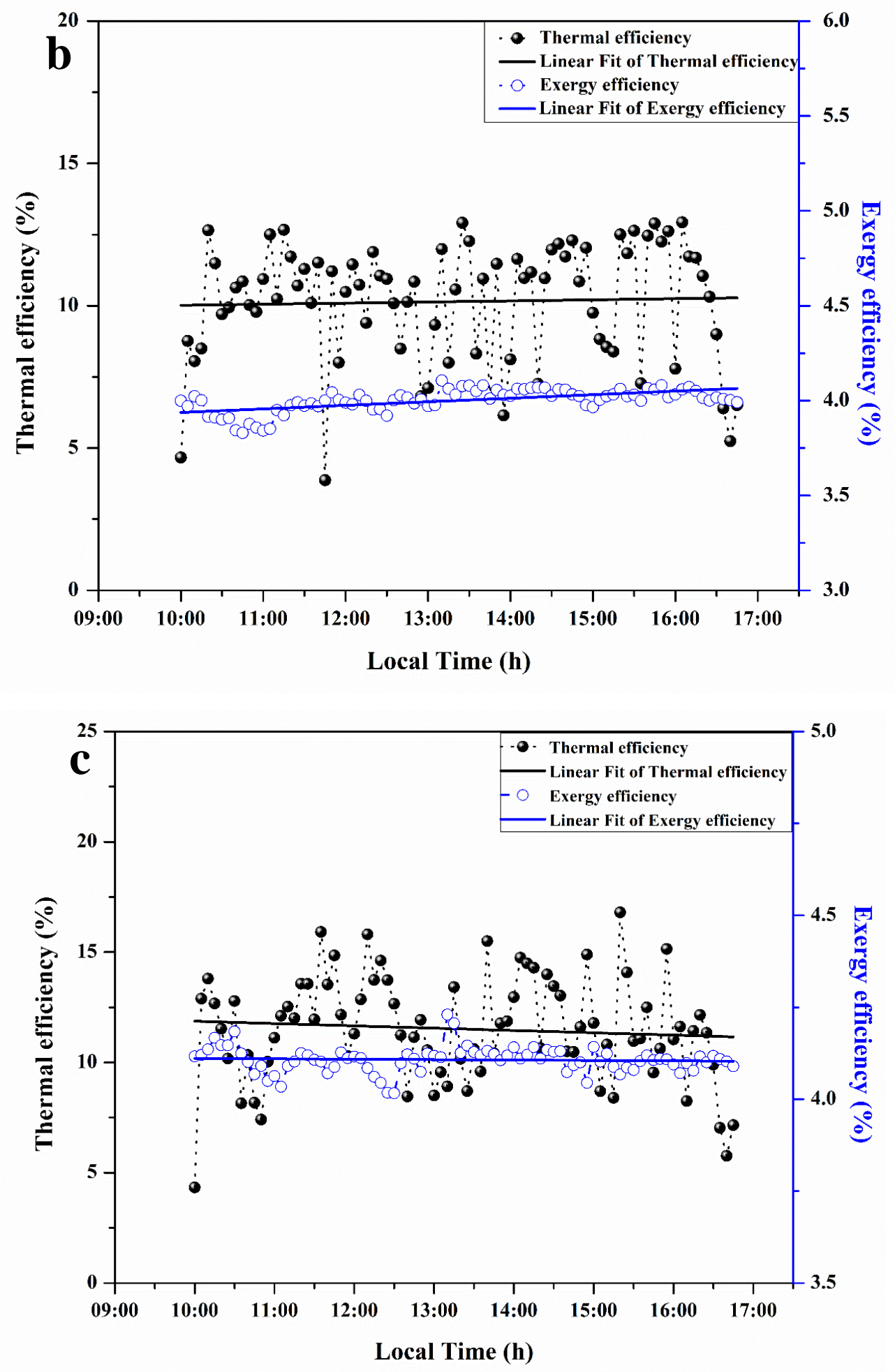

Fig. 21. Thermal and exergy efficiency of PTC run with base fluid at (a) $0.016 \mathrm{kgs}^{-1}$, (b) 0.019 


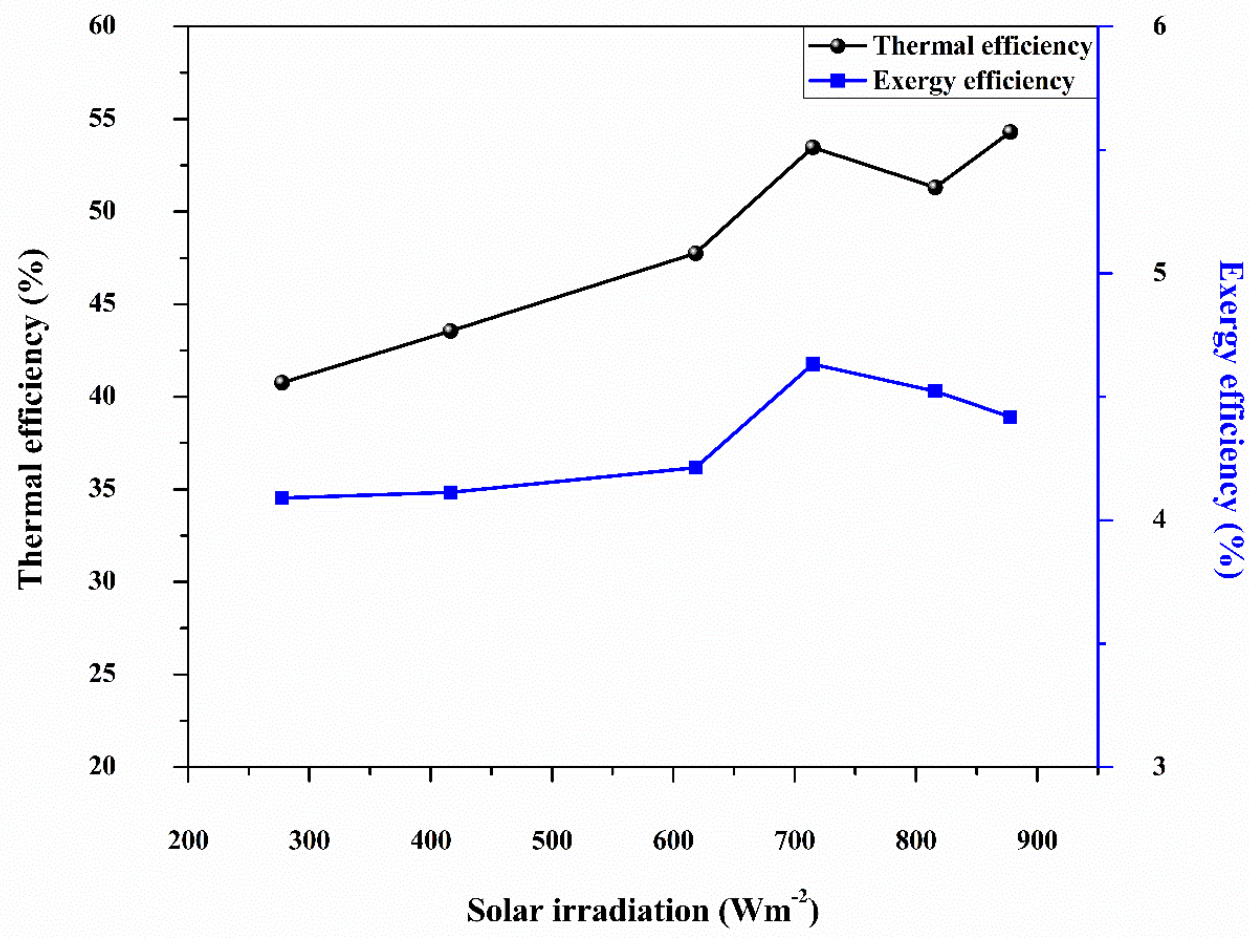

Fig. 22. Variation of thermal efficiency and exergy efficiency with solar irradiation

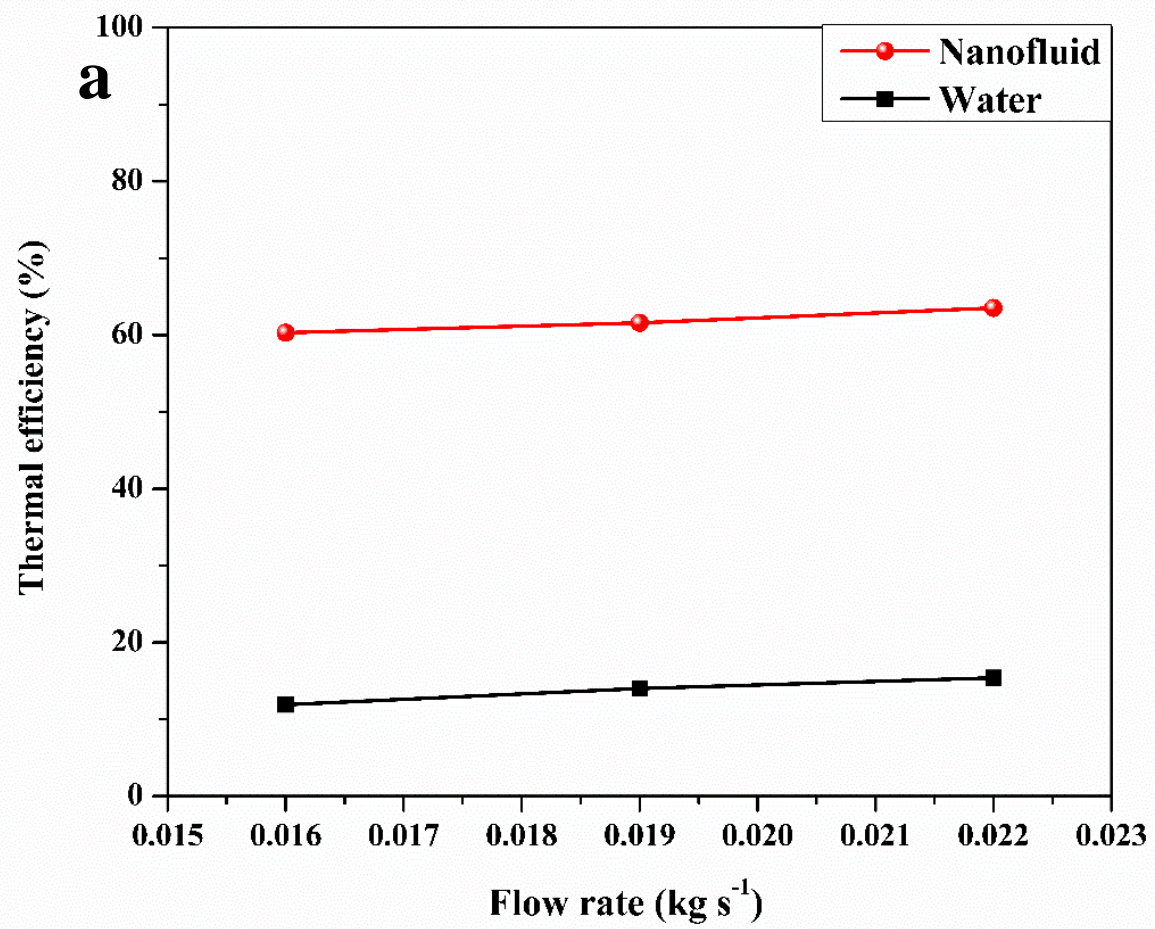




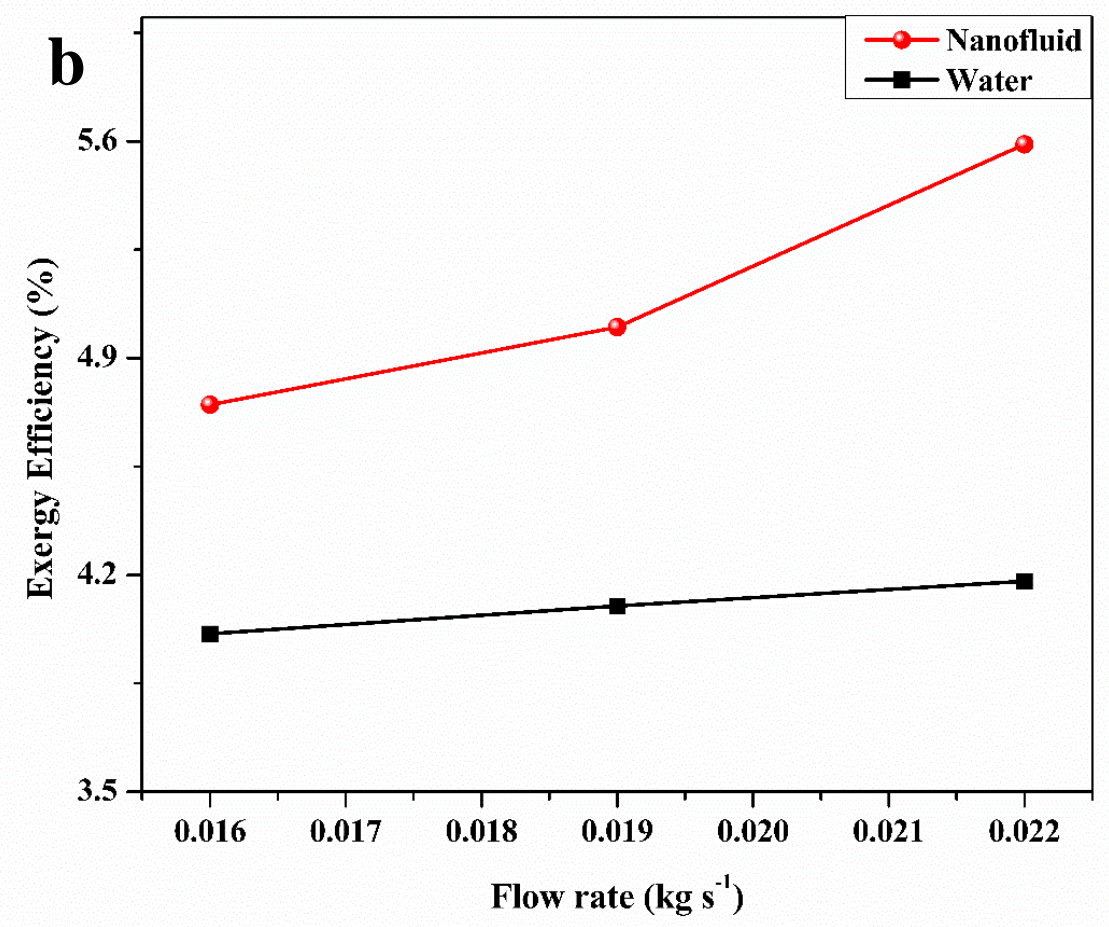

578 A trendline of thermal and exergy efficiency of the parabolic trough collector at three different 579 flow rates was generated based on the statistical linear curve fitting technique. The coefficients 580 and trendline equations of the corresponding curve are given in Table 6. The slope of the line is 581 represented by ' $b$ ', while ' $a$ ' represents the intercept of the fitted line. $\mathrm{R}^{2}$ represents the adjacent 582 R-squared value for each flow rate.

Table 6: Coefficients of efficiency curve at different flow rates

\begin{tabular}{|c|c|c|c|c|c|c|c|c|c|}
\hline \multirow{3}{*}{$\begin{array}{l}\text { Working Fluid } \\
\text { Nanofluid }\end{array}$} & \multicolumn{9}{|c|}{ Flow rate } \\
\hline & \multicolumn{3}{|c|}{$0.022 \mathrm{kgs}^{-1}$} & \multicolumn{3}{|c|}{$0.019 \mathrm{kgs}^{-1}$} & \multicolumn{3}{|c|}{$0.016 \mathrm{kgs}^{-1}$} \\
\hline & $\mathbf{R}^{2}$ & $\mathbf{a}$ & b & $\mathbf{R}^{2}$ & $\mathbf{a}$ & b & $\mathbf{R}^{2}$ & $\mathbf{a}$ & b \\
\hline \multirow[t]{2}{*}{ Thermal efficiency } & 0.587 & 33.62 & 0.30 & 0.675 & 26.18 & 3.12 & 0.573 & 27.4 & 2.52 \\
\hline & \multicolumn{3}{|c|}{$\eta_{t h}=a+b \Delta T$} & \multicolumn{3}{|c|}{$\eta_{t h}=a+b \Delta T$} & \multicolumn{3}{|c|}{$\eta_{t h}=a+b \Delta T$} \\
\hline \multirow[t]{2}{*}{ Exergy efficiency } & 0.377 & 3.89 & 0.08 & 0.586 & 3.48 & 0.084 & 0.588 & 3.45 & 0.07 \\
\hline & \multicolumn{3}{|c|}{$\eta_{e x}=a+b \Delta T$} & \multicolumn{3}{|c|}{$\eta_{e x}=a+b \Delta T$} & \multicolumn{3}{|c|}{$\eta_{e x}=a+b \Delta T$} \\
\hline
\end{tabular}


Nanofluid applied solar collectors face the problem of the settling of nanomaterial in the receiver tube. The sedimentation method, as depicted in section 5.4, validates that only a meagre deposition of nanoparticles was observed. In the present system, the nanomaterial which has sedimented on the tube surface after continuous operation for 8 hours was less. An increase in pressure drop due to higher viscosity is a setback associated with the usage of nanofluid [20]. However, the increase in pumping power due to pressure drop was found to be insignificant in the present study. Another issue is the degradation of the optical absorptivity property of nanofluid. Analysis of the retainability of nanofluid's optical absorption was performed, as given in section 6.5.

\subsection{Analysis of the degradation rate of solar weighted absorption fraction}

593 Spectral absorption analysis was employed to analyze the deterioration of stability of optimized 594 nanofluid after being deployed in the solar collector system. Transmittance spectra of nanofluid, 595 before and after running through the hydraulic cycle, is given in Fig. 29. Solar weighted absorption 596 fraction calculated for nanofluid, before and after circulation in the parabolic trough system was 597 observed to be $89 \%$ and $88 \%$ respectively. A marginal decrease in nanofluid's solar weighted 598 absorption fraction of $1.12 \%$ was observed at the end of experimentation. It is concluded that the 599 optimized concentration is not undergoing any degradation in performance due to stability or other issues even after circulating through the hydraulic loop.

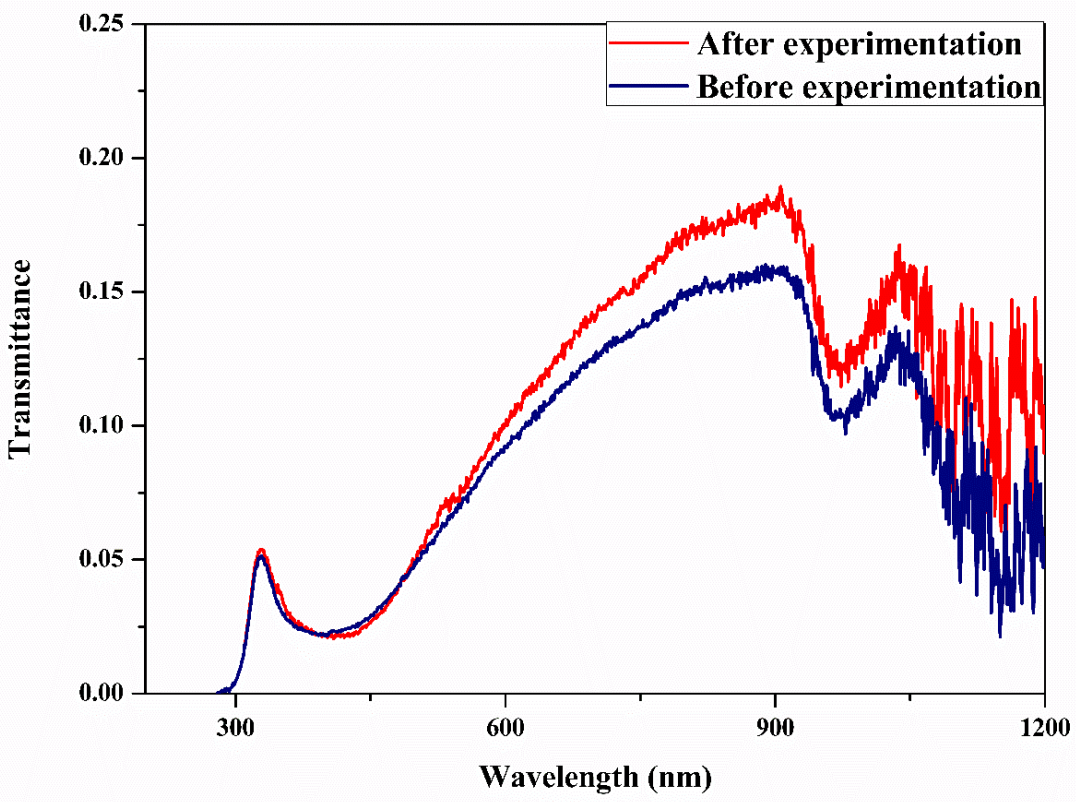

601

Fig. 24. Spectroscopic analysis of optimized nanofluid before and after experimentation in the 603 solar collector 


\section{Conclusions}

605 The synthesis and characterization of visible and NIR spectrum absorption concentrated ATO/Ag 606 hybrid nanoparticles have been performed. TEM analysis shows the morphology of silver 607 nanoparticles attached to the surface of ATO nanoparticles. XRD analysis was performed and 608 phase characterization of the hybrid nanoparticle is done. SEM-EDAX and XRD confirm the 609 presence of as stated components in the hybrid nanoparticle. RSM using Central Composite Design 610 produced a minimum of 13 sets of experimental runs. Model prediction of solar weighted absorption fraction is in agreement with the actual data obtained. The relative error between the

612 actual and the predicted value being very less validates the model predictability. Solar weighted 613 absorptivity is observed to be linearly dependent on nanoparticle concentration. The maximum 614 solar weighted absorptivity of $98.90 \%$ is obtained at $0.2 \% \mathrm{ATO} / \mathrm{Ag}$ and $0.15 \%$ SDS. The 615 optimization of concentrations of nanoparticle and surfactant was performed based on the 616 calculated solar weighted absorptivity of each run. Parametric investigation of the effect of 617 penetration depth on solar weighted absorption fraction and mass fraction on the extinction 618 coefficient was performed. Solar weighted absorption fraction was found to increase exponentially 619 with penetration depth. The extinction coefficient increased linearly with the mass fraction. 620 Investigations on direct absorption parabolic trough solar collectors yielded an optical efficiency 621 of 75\% while using ATO/Ag nanofluid. Energy and exergy efficiency were found to be a linear 622 function of the mass flow rate. The highest thermal efficiency obtained for ATO/Ag hybrid 623 nanofluid in PTDASC was $63.5 \%$. The exergy efficiency of $5.6 \%$ indicates the need to reduce 624 heat loss. The temperature difference across the receiver length decreased with an increase in flow 625 rate. $25 \%$ rise in temperature difference was reported on changing flow rate from $0.022 \mathrm{kgs}^{-1}$ to $6260.016 \mathrm{kgs}^{-1}$. It could be concluded from the obtained results, that as the flow rate increases, heat 627 loss is reduced, thereby increasing the energy and exergy efficiency.

\section{References}

[1] R.A. Taylor, P.E. Phelan, T.P. Otanicar, C.A. Walker, M. Nguyen, S. Trimble, R. Prasher, Applicability of nanofluids in high flux solar collectors, J. Renew. Sustain. Energy 3 (2) (2011) 023104. https://doi.org/10.1063/1.3571565.

[2] J.E. Minardi, H.N. Chuang, Performance of a black liquid flat-plate solar collector, Sol. 
Energy 17 (1975) 179-183. https://doi.org/10.1016/0038-092X(75)90057-2.

[3] H. Tyagi, P.E. Phelan, R. Prasher, Predicted efficiency of a low-temperature nanofluidbased direct absorption solar collector, J. Sol. Energy Eng. 131 (2009) 041004. https://doi.org/10.1115/1.3197562.

[4] T.P. Otanicar, P.E. Phelan, J. S. Golden, Optical properties of liquids for direct absorption solar thermal energy systems, Sol. Energy 83 (2009) 969-977. https://doi.org/ 10.1016/j.solener.2008.12.009.

[5] M. Chen, Y. He, J. Huang, J. Zhu, Investigation into Au nanofluids for solar photothermal conversion, Int. J. Heat Mass Transf. 108 (2017) 1894-1900. https://doi.org/10.1016/j.jijheatmasstransfer.2017.01.005.

[6] C.L.L. Beicker, M. Amjad, Enio P. Bandarra Filho, Dongsheng Wen, Experimental study of photothermal conversion using gold/water and MWCNT/water nanofluids, Sol. Energy Mater. Sol. Cells 188 (2018) 51-65. https://doi.org/10.1016/j.solmat.2018.08.013.

[7] M. Amjad, H. Jin, X. Du, D. Wen, Experimental photothermal performance of nanofluids under concentrated solar flux, Sol. Energy Mater. Sol. Cells 182 (2018) 255-262. https://doi.org/10.1016/j.solmat.2018.03.044.

[8] A.S. Abdelrazika, F.A. Al-Sulaimana, R. Saidur, Optical behavior of a water/silver nanofluid and their influence on the performance of a photovoltaic-thermal collector, Sol. Energy Mater. Sol. Cells 201 (2019) 110054. https://doi.org/10.1016/..solmat.2019.110054

[9] M. Valizade, M.M. Heyhat, M. Maerefat, Experimental comparison of optical properties of nanofluid and metal foam for using in direct absorption solar collectors, Sol. Energy Mater. Sol. Cells 195 (2019) 71-80. https://doi.org/10.1016/j.solmat.2019.01.050.

[10] N. Chen, H. Ma, Y. Li, J. Cheng, C. Zhang, D. Wu, H. Zhu, Complementary optical absorption and enhanced solar thermal conversion of CuO-ATO nanofluids, Sol. Energy Mater. Sol. Cells 162 (2017) 83-92. https://doi.org/10.1016/j.solmat.2016.12.049.

[11] F. Yu, Y. Chen, X. Liang, J. Xu, C. Lee, Q. Liang, P. Tao, T. Deng, Dispersion stability of thermal nanofluids, Prog. Nat. Sci. Mater. Int. 27 (2017) 531-542. https://doi.org/10.1016/j.pnsc.2017.08.010.

[12] X. Yu, Y. Xuan, Investigation on thermo-optical properties of $\mathrm{CuO} / \mathrm{Ag}$ plasmonic $\begin{array}{lllll}\text { nanofluids, } & \text { Sol. } & \text { Energy } & 160 \quad \text { 200-207. }\end{array}$ 
https://doi.org/10.1016/j.solener.2017.12.007.

[13] Q. Jiang, W. Zeng, C. Zhang, Z. Meng, J. Wu, Q. Zhu, D. Wu, H. Zhu, Broadband absorption and enhanced photothermal conversion property of octopod-like $\mathrm{Ag} @ \mathrm{Ag} 2 \mathrm{~S}$ core@shell structures with gradually varying shell thickness, Nature 7 (2017) 17782. https://doi.org/10.1038/s41598-017-18220-1.

[14] J. Zeng, Y. Xuan, H. Duan, Tin-silica-silver composite nanoparticles for medium-to-high temperature volumetric absorption solar collectors, Sol. Energy Mater. Sol. Cells 157 (2016) 930-936. https://doi.org/10.1016/j.solmat.2016.08.012.

[15] J. Zeng, Y. Xuan, Enhanced solar thermal conversion and thermal conduction of MWCNT-SiO $2 / \mathrm{Ag}$ binary nanofluids, Appl. Energy 212 (2018) 809-819. https://doi.org/10.1016/j.apenergy.2017.12.083.

[16] J. Zeng, Y. Xuan, Tunable Full-Spectrum Photo-thermal Conversion Features of Magnetic-Plasmonic Fe3O4/TiN Nanofluid, NANO ENERGY 2855 (18) 30522-6. https://doi.org/10.1016/j.nanoen.2018.07.034.

[17] A. Joseph, S. Mohan, C.S. Sujith Kumar, A. Mathew, S. Thomas, B.R. Vishnu, S.P. Sivapirakasam, An experimental investigation on pool boiling heat transfer enhancement using sol-gel derived nano-CuO porous coating, Exp. Therm. Fluid Sci. 103 (2019) 3750. https://doi.org/10.1016/j.expthermflusci.2018.12.033.

[18] M. Hemmat Esfe, M. Firouzi, H. Rostamian, M. Afrand, Prediction and optimization of thermophysical properties of stabilized A12O3/antifreeze nanofluids using response $\begin{array}{lllllll}\text { surface methodology, J. Mol. } & \text { Liq. } & 261 & \text { (2018) } & \text { 14-20 }\end{array}$ https://doi.org/10.1016/j.molliq.2018.03.063.

[19] T.P Otanicar, Direct absorption solar thermal collectors utilizing liquid-nanoparticle suspensions. Doctor of Philosophy, Arizona State University; 2009.

[20] A.A. Minea, W. M. El-Maghlany, Influence of hybrid nanofluids on the performance of parabolic trough collectors in solar thermal systems: Recent findings and numerical comparison, Renew. $\quad$ Energy 1481

31297-1. https://doi.org/10.1016/j.renene.2017.12.093. 
[21] E. Bellos, C. Tzivanidis, Thermal analysis of parabolic trough collector operating with mono and hybrid nanofluids, Sustain. Energy Technol. Assess. https://doi.org/10.1016/j.seta.2017.10.005.

[22] S. Delfani, M. Karami, M.A. Akhavan-Bahabadi, Performance characteristics of a residential-type direct absorption solar collector using MWCNT nanofluid, Renew. Energy 87 (2016) 754-764. https://doi.org/10.1016/j.renene.2015.11.004.

[23] M. Vakili, S. M. Hosseinalipour, S. Delfani, S. Khosrojerdi, and M. Karami, Experimental investigation of graphene nanoplatelets nanofluid-based volumetric solar collector for domestic hot water systems, Sol. Energy 131 (2016) 119-130. https://doi.org/10.1016/j.solener.2016.02.034.

[24] A. Menbari, A.A. Alemrajabi, A. Rezaei, Heat transfer analysis and the effect of $\mathrm{CuO} /$ Water nanofluid on direct absorption concentrating solar collector, Appl. Therm. Eng. 104 (2016) 176-183. https://doi.org/10.1016/j.applthermaleng.2016.05.064.

[25] A. Menbari, A.A. Alemrajabi, A. Rezaei, Experimental investigation of thermal performance for direct absorption solar parabolic trough collector (DASPTC) based on

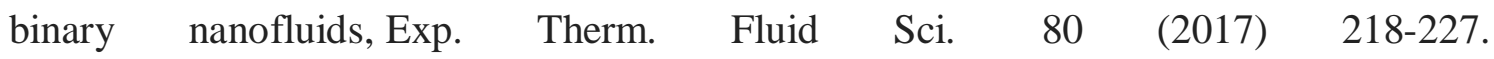
https://doi.org/10.1016/j.expthermflusci.2016.08.023.

[26] S.A. Kalogirou, S. Karellas, V. Badescu, K. Braimakis, Exergy analysis on solar thermal systems: A better understanding of their sustainability. Renew Energy 85 (2016) 132833. https://doi.org/10.1016/j.renene.2015.05.037.

[27] T.B. Gorji, A.A. Ranjbar, Thermal and exergy optimization of a nanofluid-based direct absorption solar collector, Renew. Energy $106 \quad$ (2017) 274-287. https://doi.org/10.1016/j.renene.2017.01.031.

[28] M. Karami, Experimental investigation of first and second laws in a direct absorption solar collector using hybrid Fe3O4/SiO2 nanofluid, J Therm Anal Calorim 136 (2019) 661-667. https://doi.org/10.1007/s10973-018-7624-x.

[29] Z. Zhang, Y. Ma, X. Bu, Q. Wu, Z. Hang, Z. Dong, X. Wu, Facile one-step synthesis of $\mathrm{TiO} 2 / \mathrm{Ag} / \mathrm{SnO} 2$ ternary heterostructures with enhanced visible light photocatalytic activity, Nature 8 (2018)10532. https://doi.org/10.1038/s41598-018-28832-w. 
[30] M. Kosmulski, Isoelectric points and points of zero charge of metal (hydr)oxides: 50 years after Parks' review, Adv. Colloid Interface Sci. 238 (2016) 1-61. https://doi.org/10.1016/j.cis.2016.10.005.

[31] A. R. Mallah, S. N. Kazi, M. N. M. Zubir, A. Badarudin, Blended morphologies of plasmonic nanofluids for direct absorption applications, Appl. Energy 229 (2018) 505521. https://doi.org/10.1016/j.apenergy.2018.07.113.

[32] W.D. Drotning, Optical properties of solar-absorbing oxide particles suspend in a molten salt heat transfer fluid, Sol. Energy 20 (1978) 313-319. https://doi.org/10.1016/0038092X(78)90123-8.

[33] ASTM G173-03, Standard Tables for Reference Solar Spectral Irradiances: Direct Normal and Hemispherical on 37 Tilted Surface, ASTM International, West Conshohocken, 2012.

[34] P.D. Nasab, A.R. Kelishami, J. Safdari, H. Abolghasemi, Application of emulsion nanofluids membrane for the extraction of gadolinium using response surface $\begin{array}{llllll}\text { methodology, } & \text { J. } & \text { Mol. } & \text { Liq. } & 244 & \text { (2017) 368-373. }\end{array}$ http://dx.doi.org/10.1016/j.molliq.2017.08.127.

[35] X. Lei, J. Shuang, P. Yang, Y. Liu, Parametric study and optimization of dimpled tubes based on Response Surface Methodology and desirability approach, Int. J. Heat Mass Transf. 142 (2019) 118453. https://doi.org/10.1016/j.ijheatmasstransfer.2019.118453.

[36] M.U. Sajid, H. M. Ali, Thermal conductivity of hybrid nanofluids: A critical review, Int. J. Heat Mass Transf. $126 \quad$ (2018) 211-234. https://doi.org/10.1016/j.ijheatmasstransfer.2018.05.021.

[37] M.S. Bretado de los Rios, C.I. Rivera-Solorio, A.J. García-Cu_ellar, Thermal performance of a parabolic trough linear collector using Al2O3/H2O nanofluids, Renew. Energy 122 (2018) 665-673. https://doi.org/10.1016/j.renene.2018.01.094

[38] A. Kasaeian, S. Daviran, R. D. Azarian, A. Rashidi, Performance evaluation and nanofluid using capability study of a solar parabolic trough collector, J. Clean. Prod. 89 (2015) 368-375. https://doi.org/10.1016/j.enconman.2014.09.056.

[39] ASHRAE Standard 93. Method of testing to determine the thermal performance of solar collectors. Atlanta (GA): American Society of Heating, Refrigerating and AirConditioning Engineers; 2010. 
[40] R. Petela, Exergy of undiluted thermal radiation, Sol. Energy 74 (2003) 469-488. https://doi.org/10.1016/S0038-092X(03)00226-3.

[41] I. Ceylan, A. Ergun, Thermodynamic analysis of a new design of temperature controlled parabolic trough collector, Energy Convers. Manag. 74 (2013) 505-510. https://doi.org/10.1016/j.enconman.2013.07.020.

[42] Q. Wang, M. Hu, H. Yang, J. Cao, J. Li, Y. Su, G. Pei, Energetic and exergetic analyses on structural optimized parabolic trough solar receivers in a concentrated solar thermal $\begin{array}{lllll}\text { collector } & \text { system, } & \text { Energy, } & 171 & \text { (2019) 611-623. }\end{array}$ https://doi.org/10.1016/j.energy.2018.12.211.

[43] R. J. Moffat, Describing the uncertainties in the experimental results, Exp. Therm. Fluid Sci. 1 (1985) 3-17. https://doi.org/10.1016/0894-1777(88)90043-X.

[44] M. Chafie, M.F.B. Aissa, A. Guizani, Energetic end exergetic performance of a parabolic trough collector receiver: An experimental study, J. Clean. Prod. 171 (2018) 285-296.

[45] M. Fana, H. Lianga, S. Youa, H. Zhanga, B.Yinb, X. Wu, Applicability analysis of the solar heating system with parabolic trough solar collectors in different regions of China, Appl. Energy 221 (2018) 100-111. https://doi.org/10.1016/j.apenergy.2018.03.137. 